\title{
Revised generic placement of Brachypelma embrithes (Chamberlin \& Ivie, 1936) and Brachypelma angustum Valerio, 1980, with definition of the taxonomic features for identification of female Sericopelma Ausserer, 1875 (Araneae, Theraphosidae)
}

\author{
Ray Gabriel', Stuart J. Longhorn' \\ I Hope Entomological Collections, Oxford University Museum of Natural History (OUMNH), Parks Road, \\ Oxford, England, OX1 3PW, United Kingdom
}

Corresponding author: Stuart J. Longhorn (sj1197@hotmail.com)

Academic editor: J. Miller | Received 24 August 2015 | Accepted 22 September 2015 | Published 12 October 2015

http://zoobank.org/BA29348F-1339-413E-8F16-B08F78DB167D

Citation: Gabriel R, Longhorn SJ (2015) Revised generic placement of Brachypelma embrithes (Chamberlin \& Ivie, 1936) and Brachypelma angustum Valerio, 1980, with definition of the taxonomic features for identification of female Sericopelma Ausserer, 1875 (Araneae, Theraphosidae). ZooKeys 526: 75-104. doi: 10.3897/zookeys.526.6315

\begin{abstract}
The tarantula genus Sericopelma was originally defined based on male specimens, most notably lacking tibial spurs on leg I. Early female specimens were unrecognised as Sericopelma, and typically placed in Eurypelma - a dumping ground for problem specimens. The first females were only later recognised, but authors failed to adequately define female Sericopelma. Here, the holotypes of the Southern-most alleged Brachypelma species, B. embrithes (Chamberlin \& Ivie, 1936) and B. angustum Valerio, 1980 were examined, and finding both to possess defining characteristics of Sericopelma were transferred. The taxonomic attributes to define Sericopelma relative to Brachypelma and select other Neotropical genera are discussed, especially for females. As important diagnostic characters for Sericopelma, the single (unilobar) spermathecae swollen at the apex forming a P-shaped cross-section, metatarsus IV with trace scopula, femur IV with a dense retrolateral pad of plumose hair, plus other attributes. Some past confusion in these characters are clarified and Sericopelma relative to Brachypelma and Megaphobema mesomelas are discussed. Finally recommendations are given about these taxonomic changes for CITES regulations.
\end{abstract}

\section{Keywords}

Spider taxonomy, Theraphosidae, Brachypelma, transfer, Sericopelma

Copyright Ray Gabriel, Stuart J. Longhorn. This is an open access article distributed under the terms of the Creative Commons Attribution License (CC BY 4.0), which permits unrestricted use, distribution, and reproduction in any medium, provided the original author and source are credited. 


\section{Introduction}

Sericopelma Ausserer, 1875 was established for a male tarantula from an unspecified location in Panama without leg I tibial apophyses, named S. rubronitens Ausserer, 1875. Sericopelma was originally a subgenus of Eurypelma Koch, 1851, but later given full generic status (Simon 1892). Karsch (1880) also described an early male tarantula from Chiriquí Panama without leg I tibial apophyses as Theraphosa panamana Karsch, 1880. In revision, Simon (1892) synonymized T. panamana into Ausserer's Sericopelma rubronitens, emphasizing the lack of male tibial apophyses. He also considered that another male in the Paris collection from Chiriquí, Panama, might be the same. Like Karsch, he drew on similarities to the genus Theraphosa, where males of T. blondi (Latreille, 1804) also lack tibial apophyses, but distinguished the genera by several other features such as bulb shape, eye ratios, and cephalothorax dimensions. Soon after, Pickard-Cambridge (1897) described another species from four males also collected around Chiriquí province in Panama, which he named Sericopelma commune F.O.P.-Cambridge, 1897 . He distinguished Sericopelma by femur IV "with a thick scopuliform pad on inner side", male tibia I without spurs, and emphasized the lack of scopulae on protarsus (metatarsus) of leg IV "with no thick scopulae on the inner side". Pocock (1901) again treated Sericopelma as congeneric with Theraphosa, but was not subsequently accepted.

Throughout the early twentieth century, only male Sericopelma were formally known and females remained unrecognised. Simon had described Eurypelma panamense Simon (1891) from a female with the vague locality of "Panama, Guatemala" emphasising conspicuous scopulae on femural leg IV, but failed to recognize it as Sericopelma (see Gabriel 2009). Schiapelli and Gerschman de Pikelin (1967) then evaluated both sexes of a Sericopelma sp. from "Rio Grande, Nicaragua" (? = Río Grande de Matagalpa) and illustrated the first female spermathecae. Next, Valerio (1980) described seven new Costa Rican species including three from both sexes, namely Sericopelma generala, S. immensum and S. silvicola, but only males for $S$. dota, S. ferrugineum, S. melanotarsum and S. upala. Following Schiapelli and Gerschman (1967), Sericopelma was characterized in Valerio (1980) by the "presence of a thick scopula on the inner side of femur IV, and by the absence of spurs on tibia I [of males], and by the absence of stridulatory setae on trochanter I, and [absence of] scopula on metatarsus IV'. Smith (1991b) then re-described a syntype male of $S$. commune and illustrated the spermathecae of a female Sericopelma sp. in the BMNH collection. He suggested the latter was the un-described female of $S$. commune, and although stating "not a species description", it has been subsequently treated as such (i.e. World Spider Cata$\log 2015)$. We deduce that Smith (1991b) was referring to a female from Pozo Azul de Pirrís, Costa Rica, assigned by Valerio to $S$. immensum [see discussion]. Schmidt (1994) described the exuvia of a female as $S$. melanotarsum, illustrating the spermathecae, but did not give collection locality nor list any museum deposit. Most recently, Gabriel (2009) transferred the Panamanian Sericopelma panamense (Simon, 1891) from Eurypelma, illustrating the holotype spermathecae plus of another Panamanian Sericopelma sp. from Boquete, Chiriquí province, whilst Gabriel and Longhorn (2011) illustrated the spermathecae of a Sericopelma sp. from Bocas del Toro province, Panama. Finally Andre and 
Esche (2011) showed the spermathecae of S. melanotarsum alongside other morphological data, plus substantial ecological, behavioural, and captive breeding data. However, despite these studies, Sericopelma as a whole remains poorly defined.

The genus Brachypelma Simon, 1891 was created for Mygale emilia White, 1856, originally listed from Panama. However, this location is erroneous, as the natural distribution of the type species and allies is South-western México (i.e. Smith 1994, Locht et al. 1999, Schmidt 2003). Brachypelma is currently said to range from México to Panama, though the southern-most species have not been revised until now. PickardCambridge (1897) could not distinguish Brachypelma from Eurypelma, and considered the genera synonymous, describing other species such as B. smithi (F.O.P.-Cambridge, 1897), which has become a flagship for conservation efforts under the Convention on International Trade in Endangered Species (CITES). Eurypelma was partly dismembered by Pocock (1903), who recognised the importance of plumose hairs on leg I and palp to define Brachypelma, whilst Simon (1903) admitted Eurypelma was previously insufficiently characterised. Brachypelma was considered valid by Valerio (1980) who described three new species from Costa Rica, B. albopilosum Valerio, 1980, B. fossorium Valerio, 1980 and B. angustum Valerio, 1980. Soon after, Smith (1986) formalised additional transfers from Eurypelma to Brachypelma. Valerio (1980) had previously also transferred the Costa Rican Eurypelma mesomelas O.P.-Cambridge, 1892 into Brachypelma and described the female. Smith $(1986,1987)$ agreed, but not Schmidt (1991a/b), who further transferred it to Megaphobema despite objections by Smith (1991a/b). Schmidt $(1993,2003)$ continued to list this as Megaphobema mesomelas, as does the current World Spider Catalog (World Spider Catalog 2015).

Here taxonomic placement of some Costa Rican and Panamanian species is re-evaluated. Petrunkevitch (1925) had previously recorded several alleged Eurypelma from Panama, listing some as species now placed in Brachypelma (namely emilia, sabulosum and vagans) since known only from México, Guatemala and Belize (Smith 1994, Locht et al. 1999). Chamberlin and Ivie (1936) went further and described a species from Barro Colorado Island [Panama] as Eurypelma embrithes, placing it in that genus without explanation. Already, the robustness of Eurypelma should have been suspicious, as many species had been placed there without justification. Petrunkevitch (1939) later considered Eurypelma as "genus incertum and invalidum", although was treated as valid by Roewer (1942). Raven (1985) went on to regard Eurypelma as a junior synonym of the arboreal Avicularia Lamarck, 1818. Consequently several species were transferred to Avicularia that clearly did not belong there. Schmidt (1993) instead transferred several former Eurypelma into Aphonopelma, leading to the new combination Aphonopelma embrithes (Chamberlin \& Ivie, 1936) although gave no justification, nor apparently examined any relevant types. Smith (1994) relocated embrithes to Brachypelma after reviewing many historical specimens, but did not explain his placement of this Panamanian species, thereby becoming the southern-most representative of Brachypelma. However, B. embrithes has since been listed as such (e.g. World Spider Catalog 2015) and receives legal protection under CITES legislation. However, much taxonomic revision is necessary for this protected genus in the context of others genera such as Sericopelma, 
although Smith (1994), Locht et al. (1999) and West (2005) have each made valuable contributions. Here, type material of B. embrithes and B. angustum are re-examined and their taxonomic placement is reconsidered in a modern context.

\section{Methods}

Specimens were examined under a binocular microscope, photographs of spermathecae and other structures were typically made using a Leica M135 auto-montage system, other photographs with a Fujipix S5000. All measurements are given in millimetres (mm). Abbreviations, Institutes: AMNH = American Museum of Natural History; BMNH = British Museum of Natural History; CNAN = Colección Nacional de Arácnidos, Instituto de Biología, Universidad Nacional Autónoma de México; LAAHFC = Laboratorio de Acarología "Anita Hoffmann", Facultad de Ciencias, Universidad Nacional Autónoma de México; MCZ = Museum of Comparative Zoology Harvard; MIUCR = Museo de Invertebrados University Costa Rica, MIUP = Museo de Invertebrados G.B. Fairchild, Universidad de Panama; MNHN = Muséum National d'Histoire Naturelle, Paris; OUMNH = Oxford University Museum of Natural History, UK; PMY = Peabody Museum of Natural History, Yale, Connecticut; SJLC = Private collection Stuart J. Longhorn; STRI = Smithsonian Tropical Research Institute; NHMV = Natural History Museum Vienna (Naturhistorisches Museum Wien), Austria; ZMB = Museum für Naturkunde, Berlin, Germany. Others: CITES = Convention on International Trade in Endangered Species; ANAM = Autoridad Nacional del Ambiente; B.C.I. = Barro Colorado Island; Imm = immature specimen; Ident. $=$ indeterminate; det. $=$ determined as; $\mathrm{ALE}=$ Anterior Lateral Eyes; PLE $=$ Posterior Lateral Eyes; AME $=$ Anterior Medial Eyes, $\mathrm{PLE}=$ Posterior Lateral Eyes; LHS = Left Hand side (from above); RHS = Right Hand Side. DMS = Degrees, Minutes, Seconds. Authors comments/emphases in[ ].

Type material examined: $1+$ holotype $\& 1 \mathrm{imm} q$ paratype Aphonopelma seemanni F.O.P-Cambridge 1897, BMNH [unknown accession], Puerto Culebra, Costa Rica, leg. Dr. B. Seemann; 1 q holotype Brachypelma angustum Valerio 1980, UCR433; 1 đ̂ holotype Brachypelma baumgarteni Smith 1993, BMNH 1999-122, Sierra Madre del Sur, Mexico, leg. M. Baumgarten; 1 q holotype Brachypelma embrithes (Chamberlin and Ivie 1936), AMNH [No accession], Barro Colorado Island (B.C.I), Panama, leg. unknown; 1 ก neotype Brachypelma emilia (White 1856), BMNH 9812-24-32, Ciudad (Durango, Mexico) leg. Mr. Forrer (See Smith 1994); 1 ठ̀ paraneotype B. emilia (labeled as paratype), OUNMH Jar 106, Ciudad, Mex (Durango, Mexico) leg. Forrer; 1 đ holotype Brachypelma fossorium Valerio 1980, UCR-238 Guanacaste, Gte Filadelfia, leg. 24 jul.1973, Eddie Herrera \& 1 o allotype UCR126, Guanacaste, Finca Santo Tomás, leg. 9 Apr. 1966, C.E. Valerio; 1 q holotype Brachypelma sabulosum (F.O.P.-Cambridge 1897) BMNH 1898.12.24.54, Tikal Petten (=Peten), Guatemala, leg. A.P.Maudslay; $1 \mathrm{j} \widehat{\jmath}$ holotype (originally listed as +) Brachypelma smithi (F.O.P.-Cambridge 1897), BMNH 1898.12.24.33 (1143),

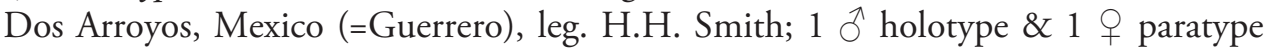


Brachypelma vagans (Ausserer 1875), BMNH 1890-7-1-380-282, Yucatan (Keyserling collection), leg. Unknown; 1 holotype Megaphobema mesomelas (O.P.-Cambridge 1892), BMNH 1898.12.24.55, Caché, Costa Rica, leg. H. Rogers, Goodman and Salvin collection [ex-dried]; 1 ô holotype, 1 ○े paratype (=syntype) Megaphobema robustum (Ausserer 1875), BMNH 1890.7.1.369-371, Bogotá [=Colombia] (Keyserling collection), leg. unknown; 10 holotype Megaphobema peterklaasi Schmidt 1994, SMF 38028 Costa Rica, leg. P. Klaas, det G. Schmidt 1994 \& 1 ô paratype SMF 38030, same data; 1 त holotype \& 1 + allotype Megaphobema velvetosoma Schmidt 1995, SMF 57910, Ecuador, area around Tena, leg. D.Antonelli; 3 ô 'syntypes' (lectotype and paralectotypes) Sericopelma commune F.O.P.-Cambridge 1897, BMNH 1898.12.24 19-21, Panama, Chiriquí, leg. G.C. Champion; 1 ô paralectotype (fourth syntype) S. commune OUMNH Jar 106, Chiriquí, leg G. Champion.; 1 O holotype Sericopelma immensum Valerio 1980, UCR-237, San José, Cantón Dota, Finca El Cedral 2100 m, leg. 28 Oct. 1972, Guillermo Solís \& 1 q allotype UCR-288, San José, Cantón Puriscal, Naranjal de Guarumal, 480 m, leg. 5 Apr. 1972, Luis E. Jirón; 1 q holotype Sericopelma panamense (Simon 1891), AR 4850 MNHN (Simon Collection), 'Panama and Guatemala' leg. unknown; 1 Tे holotype Sericopelma panamanal um (Karsch 1880), ZMB 2394 BERLIN = Junior synonym of S. rubronitens by Simon (1892), Panama, Chiriquí, leg. Unknown; 1 đ holotype Sericopelma rubronitens Ausserer 1875, NHMV Nr.1874.III.1, WIEN, Panama, leg. unknown.

Other material examined: See supplement for full listing of examined Nicaraguan, Costa Rican and Panamanian Sericopelma spp. in the collections at BMNH, MCZ, MNHN, MIUP, OUMNH, PMY, SJLC. Specimens of various Brachypelma sp. from BMNH, CNAN, MCZ, OUMNH, LAAHCF, SJLC, Megaphobema sp. from MCZ, OUMNH, SJLC and Theraphosa sp. from OUMNH and SJLC.

\section{Results}

\section{Taxonomy}

\section{Family Theraphosidae Thorell, 1869 \\ Genus Sericopelma Ausserer, 1875}

\section{Sericopelma embrithes (Chamberlin \& Ivie, 1936), comb. $\mathbf{n}$.}

Eurypelma embrithes Chamberlin \& Ivie, 1936: 7 (D female)

Avicularia embrithes Raven, 1985: 146, 148, 151 (T f from Eurypelma). Aphonopelma embrithes Schmidt, 1993: 78 ( T f from Eurypelma = Avicularia). Brachypelma embrithes Smith, 1994: 160 ( $\mathrm{T}$ f from Eurypelma = Avicularia).

Description. Female (Holotype AMNH): Total length including chelicerae 58.6. Carapace, length 27.6, width 23.2. Caput, high. Ocular tubercle, length 2.6, width 3. An- 

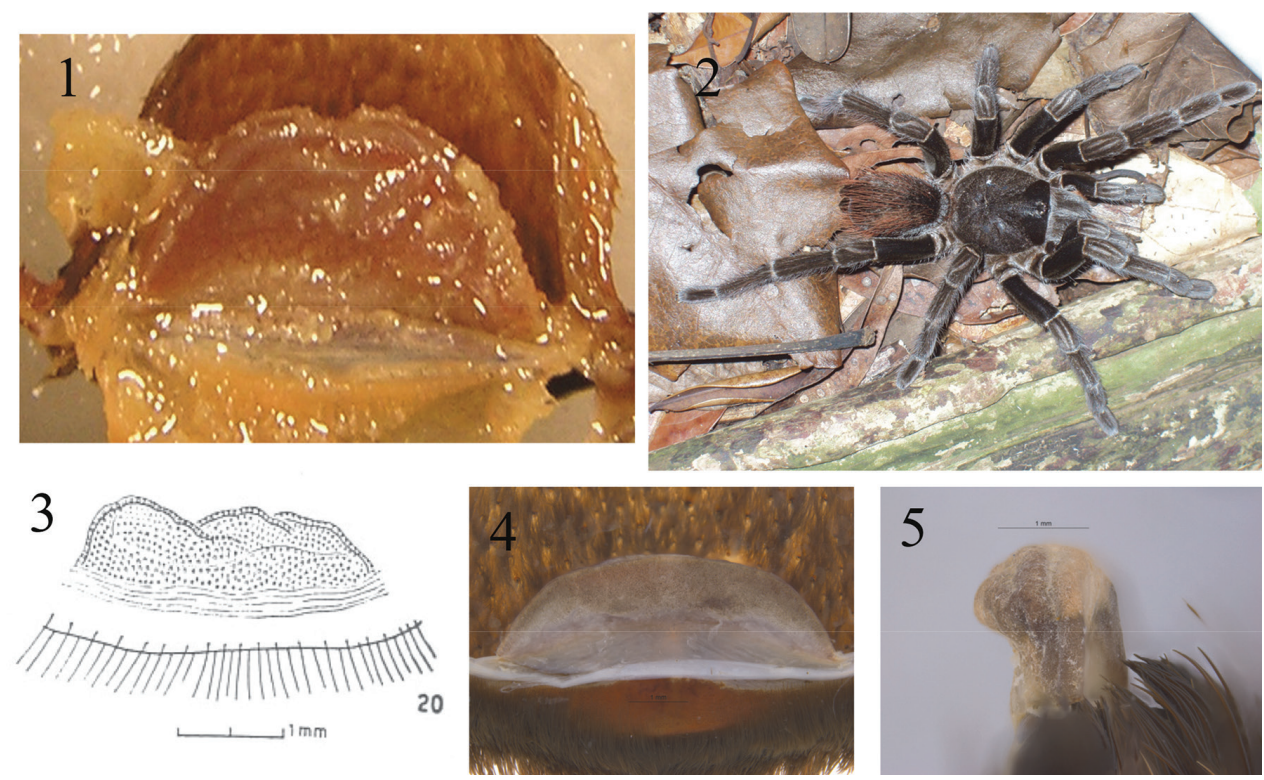

Figure 1-5. I Spermathecae from holotype of $S$. embrithes in dorsal view $\mathbf{2}$ Live specimen in situ of Sericopelma cf. embrithes at type locality on Barro Colorado Island, probable adult Female [Photo: Insa Wagner, STRI] 3 Spermatheca drawing of female Nicaraguan Sericopelma sp. in dorsal from Schiapelli and Gerschman (1967), their figure 204 Spermatheca of mature female Sericopelma sp. Boquete $\left(8.78^{\circ} \mathrm{N}\right.$, $\left.82.43^{\circ} \mathrm{W}\right)$, Districto Boquete, Chiriquí Province, Panama, dorsal view lacking any distinct median notch 5 Same spermatheca (as 4) in lateral view with diagnostic 'P-shape' (of seen in reverse).

terior row procurved, posterior row recurved. Eyes ALE > AME, AME > PLE, PLE > PME. Clypeus; 0.9, clypeal fringe long. Fovea, deep transverse. Maxillae, with 100-120 cuspules, covering approximately $60 \%$ of proximal edge. Labium, length 3.2, width 4.4, with 40-60 labial cuspules most separated by less than 0.5 - 1 times the width of a single cuspule. Labio-sternal mounds separate. Sternum, damaged with three pairs of sigilla. Femur IV with a dense pad of plumose hair on retro-lateral surface, pro-lateral surfaces of trochanter/femur of anterior legs lacking stridulatory setae. Tarsi I-IV densely scopulate. Metatarsal scopulae, I 88\%, II 83\%, III 64\%, IV 15\% of the length of the segment, IV divided. Lengths of leg and palpal segments see Table 2. Spination: femurs I, III, IV, 0-02 palp d 0-0-1, patella I, palp, II, III 0-2-0, IV 0-3-0, tibia $1 \mathrm{~d}$ 0-2-0, v 0-0-3, II d 1-2-0, v 1-1-3, III d 2-2-2, v 0-2-3 (apical), tibia IV d 4-3-2, v 2-1-2, palp d 0-1-2, metatarsus I 0-0-1, II v 0-0-2 (apical), III d 2-3-2, v 4-0-5 (apical), IV d 3-2-2, v 5-5-9 (5 apical). Posterior lateral spinnerets, with three segments, basal 4.4, medial 3.7, digitiform apical 6.1.Lateral median spinnerets, with one segment. Spermathecae, single domed receptacle apically swollen (Fig. 1). Urticating hairs (not from holotype) type I and III.

Colour. Type specimen alcohol faded brown. Live freshly moulted specimens from type locality are an overall blackish with longer red hairs on the abdomen, with grayish hairs on the dorsal trochanter, coxae and edges of the carapace, and two converging stripes on patella in older specimens (Fig. 2). These colours fade to overall 
Table I. S. embrithes female holotype lengths of legs and palp.

\begin{tabular}{c|c|c|c|c|c}
\hline & I & II & III & IV & Palp \\
\hline Femur & 17.9 & 17.5 & 14.8 & 19.9 & 14.5 \\
\hline Patella & 10.8 & 9.7 & 8.7 & 10.6 & 9.0 \\
\hline Tibia & 12.7 & 13.2 & 11.3 & 15.5 & 9.8 \\
\hline Metatarsus & 12.7 & 12.2 & 14.6 & 21.3 & - \\
\hline Tarsus & 9.9 & 9.8 & 9.8 & 11.0 & 11.1 \\
\hline Total & 64.0 & 62.4 & 59.2 & 78.3 & 44.4 \\
\hline
\end{tabular}

brown with subdued russet abdominal hairs after a few months and the first dry season (RG pers.obs.).

Distribution. Only known from type locality Barro Colorado Island, = Lake Gatun/ Canal Zone, Districto La Chorrera, Provincia de Panamá, República de Panamá [DMS = 9 $\left.09^{\prime} 00^{\prime \prime} \mathrm{N}, 79^{\circ} 50^{\prime} 41^{\prime \prime} \mathrm{W}\right]$.

Remarks. Originally, this species was described by "Carapace is decidedly longer than wide. Median depression transverse; deep" and "barely a trace of scopula on metatarsus IV". Our examination confirmed these features, but lead us to conclude identification as Sericopelma as defined here, including presence of an apically swollen unilobar spermathecae (Fig. 1, see also Figs 3-5, 7-9, contrast 13-16). The type locality of Barro Colorado Island is the site of a Smithsonian Institute field-centre; hence there is a large series of specimens from type locality assignable to Sericopelma embrithes (Fig. 2) in the MCZ, MIUP and PMY (supplementary material). It is possible that S. embrithes (Chamberlin and Ivie 1936) is a junior synonym of another Sericopelma sp. such as $S$. commune PickardCambridge, 1897 or S. panamanum (Karsch, 1880). Unfortunately, the mature male of $S$. embrithes remains unknown. However, geographic considerations can be vital to make confident decisions about both generic and species identities as many tarantulas have narrow distributions, and we contend these older named Panamanian species were collected in distant western Panama, namely 'Chiriqui', likely the cool highlands near Volcán Baru and Boquete (Prov. de Chiriquí) where Europeans would acclimatize (rather than the small modern village of Chiriquí, Prov. de Chiriquí). Conversely, S. embrithes from Barro Colorado Island (Prov. de Panamá) is within the central Canal Zone, a distance of over $300 \mathrm{~km}$ from 'Chiriquí' (Specifically ca. $320 \mathrm{~km}$ from Panama City to Boquete).

\section{Sericopelma angustum (Valerio, 1980), comb. $\mathbf{n}$.}

Brachypelma angusta Valerio, 1980: 269, f. 19. (D female) Euathlus angustus: Raven 1985: 150 (T f from Brachypelma). Brachypelma angustum: Schmidt 1992: 10, f. 8 (T f from Euathlus). Brachypelma angustum: Schmidt 1993: 82, f. 192. (misidentification*) [*Note: The figure 'Abb. 192' in Schmidt 1993 shows a spermathecae of an alleged B. angustum, but does not conform to either the Valerio's (1980) drawing of the 
holotype spermathecae, nor our examination of the type. We suggest the material of Schmidt (1993) was likely misidentified pet trade Brachypelma sp. as with discussion and figures in Peters $(2000,2003)$, also misidentified pet trade Brachypelma sp.]

Description. Female (Holotype UCR 433): Total length including chelicerae 58.9. Carapace, length 22.9, width 19.2.Caput, high. Ocular tubercle, length 2.6, width 3.1. Anterior row procurved, posterior row recurved. Eyes, ALE > PLE, PLE > AME, AME $>$ PME. Clypeus, 0.5, clypeal fringe long. Fovea, deep transverse. Maxillae, with 80-100 cuspules, covering approximately $60 \%$ of proximal edge. Labium, length 2.9, width 3.7, with 21 labial cuspules (a bald area in the centre of the labium lacks sockets for cuspules and may indicate previous damage, this cannot be confirmed until further specimens are examined) most separated by less than $0.5-1$ times the width of a single cuspule. Labio-sternal mounds separate. Sternum damaged, narrow, length 10.2 (approx), width 8.4 with three pairs of sigilla. Femur IV with a dense pad of plumose hair on retro-lateral surface, pro-lateral surfaces of trochanter/femur of anterior legs lacking stridulatory setae. Tarsi I-IV densely scopulate, tarsus IV with spines along central axis. Metatarsal scopulae, I 84\%, II 78\%, III 35\%, of the length of the segment, IV lacking scopulae. Lengths of leg and palpal segments see Table 1. Spination: femurs I, II, IV d 0-0-1, III 0-0-4, palp $0-0-2$ (no spines on LHS palp only on RHS palp), patella II, palp $0-1-0$, III 1-1-0, tibia I d 0-2-0, v 4-3-3, II d 1-1-1, v 2-4-3, III d 2-2-2, v 3-5-3, tibia IV d 2-0-4, v 4-4-3, palpal tibia d 0-2-1, v 2-2-4 (apical), metatarsus I v 2-0-3, II d 0-1-1, v 2-1-3(apical), III d 3-3-2, v 3-5-10 (6 apical), IV d 6-5-4, v 8-11-16 (6 apical). Posterior lateral spinnerets with three segments, basal 3.9, medial 3.2, digitiform apical 5.1.Lateral median spinnerets with one segment. Spermathecae, single domed receptacle apically swollen with slight medial indentation. Urticating hairs, type I and type III present.

Colour. Alcohol faded brown, posterior legs III and IV with longer reddish setae.

Distribution. Only known from type locality San Pedro de Arenal, Cantón San

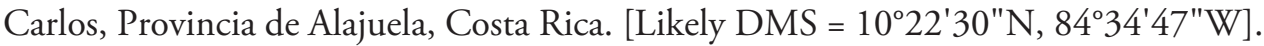

Remarks. The holotype is now fragmented (Figs 6-11) and right legs II and III both appear to have been lost in life as coxal stumps are blackened indicating wound healing. Accession data from UCR and jar labels specify the holotype was collected on 01-Oct.-1974 by Edgar Vargas, but this information was not given by Valerio 1980. In the holotype jar of S. angustum a label "iqual a Sericopelma upala (?) CEV 13 julio 83" (Fig. 6) shows Valerio himself (= CEV) had doubts about placement in Brachypelma, also considering it conspecific to the male he described as $S$. upala. The type localities are close, less than $50 \mathrm{~km}$ apart in Alajuela with similar ecotypes of lowland tropical forest, now largely fragmented to sugarcane plantation and cattle pasture (S. Longhorn pers. obs). However, until further specimens of Sericopelma upala and/or S. angustum are examined, we are not prepared to place them into synonymy at this time. We suspect Valerio (1980) lacked sufficient access to Brachypelma material to make a more informed decision about the genus, failing to recognise defining characteristics (as outlined below). 

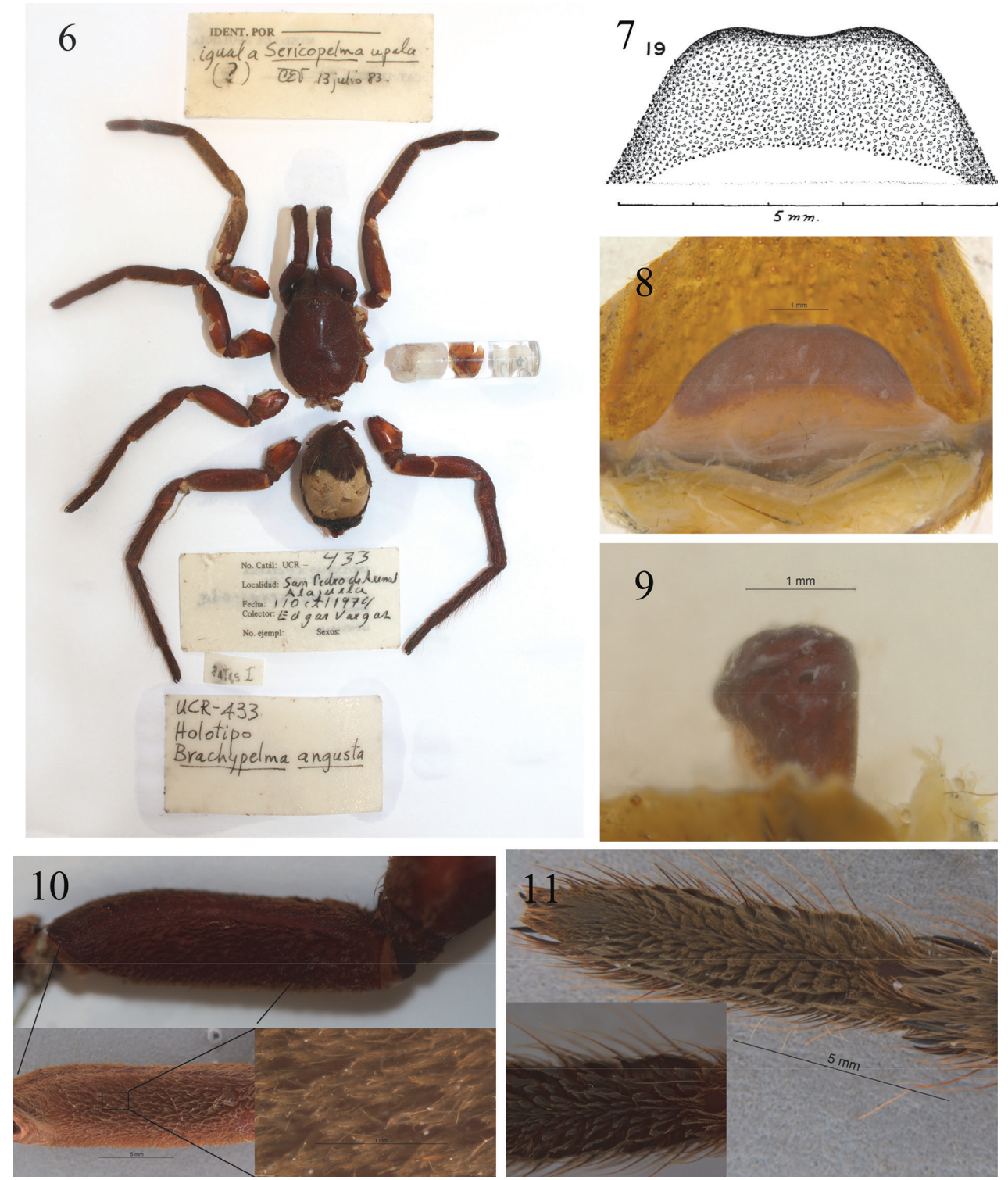

Figure 6-I I. Holotype of S. angustum. 6 Habitus and labels 7 Valerio (1980) figure 19, drawing spermathecae 8 Spermathecae, dorsal view 9 Spermathecaee, lateral view showing (reversed) 'P-shape' diagnostic of Sericopelma 10 Dense pad of plumose hairs on femur IV not present in Brachypelma, upper with alcohol wet, bottom left inset same dried, bottom right inset closeup of plumose hairs I I tarsus leg IV showing unusual spines along central axis, bottom left inset closer image. 
Table 2. S. angustum female holotype lengths of legs and palp.

\begin{tabular}{r|c|c|c|c|c}
\hline & I & II & III & IV & Palp \\
\hline Femur & 16.3 & 15.2 & 14.6 & 18.9 & 11.9 \\
\hline Patella & 9.5 & 8.9 & 8.3 & 9.7 & 7.1 \\
\hline Tibia & 14.0 & 12.0 & 11.2 & 15.1 & 9.4 \\
\hline Metatarsus & 12.0 & 12.0 & 15.0 & 22.0 & - \\
\hline Tarsus & 9.6 & 9.4 & 9.1 & 9.6 & 9.8 \\
\hline Total & 61.4 & 57.5 & 58.2 & 75.3 & 38.2 \\
\hline
\end{tabular}

\section{Sericopelma commue F.O.P.-Cambridge, 1897}

Sericopelma communis F.O.P-Cambridge: 15 (D male).

Sericopelma commune Smith, 1991b: 18 (f), here considered misplaced in this species.

Type. Male (3 male syntypes, BMNH 1898-12-24-19-21, male syntype OUMNH O.P.-Cambridge Coll. Jar 106):

Remarks. Smith (1991b) refers to three of four male syntypes from Chiriquí as $S$. commune, specifically BMNH 1898-12-24-19-21 (i.e. accessioned 24 $4^{\text {th }}-$ Dec-1898, coded '19-21'), then described a female, saying "Female BMNH 98-12-24-22. Assigned to the species by Valerio". The only female BMNH specimen with this accession has the oldest label "Museo Nacional de Costa Rica, Pozo Azul de Pirrís, José C. Zeldón", naming a collector from the 1890s. A later label "Sericopelma immensa n. sp. Det. C. E. Valerio, Jan 10, 1979 " matches his paper (Valerio 1980) referring to a BMNH specimen from this same locality as $S$. immensum. However, the species on the Valerio label has been physically scored out, but likely reads immensa. Another pen-written label says "Sericopelma commune F.O Pick-Cambr." (in handwriting of curator Doug Clark, died 1972), apparently present when both Valerio and Smith examined the specimen. We suspect this label misled Smith (1991b) to reconsider the specimen as the un-described female S. commune, even though collected at a Costa Rican locality (Parrita Cantón, Puntarenas), approx. 250 $\mathrm{km}$ from the Chiriquí type site. However Smith only records the distribution (indicating both sexes) from Chiriquí, Panama. Further confusion occurs with another mature male in BMNH with an old pencil-written label "Panama", then two pen labels in Clark's handwriting, "S. commune PDA Costa Rica BMNH 1898-12-24-22" and "Sericopelma commune det. Clark 1960". We suspect these latter labels were an attempt by Clark to wrongly allocate this "Panama" male to both the Pozo Azul de Pirrís accession, and as a 'missing' fourth male syntype of $S$. commune. Clark perhaps did not realise that fourth male is in the Pickard-Cambridge collection at OUMNH, where a male labelled 'syntype' had the unequivocal label "Sericopelma communis Fopc Chiriqui - Champion". In a BMNH accessions book, 1898-12-24-22 corresponds to "Sericopelma sp? Pozo Azul de Pirrís (Costa Rica). Pres. by F.D. Godman, Esq., Costa Rica Mus, F.O.P.-Cambridge”. However, although F.O. Pickard-Cambridge apparently recognised it as a possible female Sericopelma sp, the lack of accounts before Valerio (1980) indicate it was ignored, 
perhaps due to uncertainty about matching it with known males. We consider this female to be the same listed by both Valerio (1980) and Smith (1991b) and suggest its unsecure designation as the first described female of $S$. commune be suspended, instead to favour topotypic specimens from Chiriquí, such as the region of Volcán where G. Champion likely collected the four male syntypes.

Distribution. Only known from type locality, Chiriquí = Chiriquí, Provincia de Chiriquí, República de Panamá.

\section{Sericopelma panamanum (Karsch, 1880), stat. rev.}

Theraphosa panamana Karsch, 1880: 84 (D male).

Sericopelma panamana F. O. Pickard-Cambridge, 1897a: 16.

Sericopelma rubronitens Simon, 1892: 159 (S, here considered misplaced in this species).

Type. Male (1 male holotype, ZMB 2394 BERLIN):

Remarks. Simon (1892) makes no clear justification why Karsh's T. panamana from Chiriquí should be synonymous with $S$. rubronitens, only referring to similarities in eye pattern and absence of tibial spurs in Karsh's description against another nontype male specimen in the Paris collection, which he had assigned as S. rubronitens. Our re-examination of the type specimen confirmed its designation as a Sericopelma sp., but not its synonymy with $S$. rubronitens, which is here reversed.

Distribution. Only known from type locality, Chiriquí = Chiriquí, Provincia de Chiriquí, República de Panamá.

\section{Geographic distribution, and generic limits}

We believe it is important to re-clarify the characteristics of Brachypelma in this context. The type of Brachypelma is B. emilia, originally suggested in the paper's title to be from Panama (White 1856). A later male from México: Ventanas, Prov. de Durango (leg. Forrier) was described by Simon (1891) as generic type. Smith (1994) incorrectly says "Simon lists his specimen as coming from Panama" (p.166). We suspect this stems from a mis-listing by F.O.P-Cambridge (1897) of "PANAMA (coll. Simon: Male)" where locality was confused with the original type. While the original specimen appears lost (Smith 1994) or 'non-existent' (Pickard-Cambridge 1897), an excellent illustration in White's paper allows identification, showing an adult male with tibial spurs. The route of the collector (Berthold Seemann) is well known (Seemann 1852), joining his ship in Panama and voyaging north along the Pacific, docking in México both at San Blas (Estado Nayarit) and Mazatlán (Sinaloa). The original type taken to the BMNH was most likely collected during the second inland foray in 1849/50 to Ciudad de Durango (modern Victoria de Durango, Durango) and Tepic (Nayarit). However, another male deposited in MNHN was used as generic type of Brachypel- 


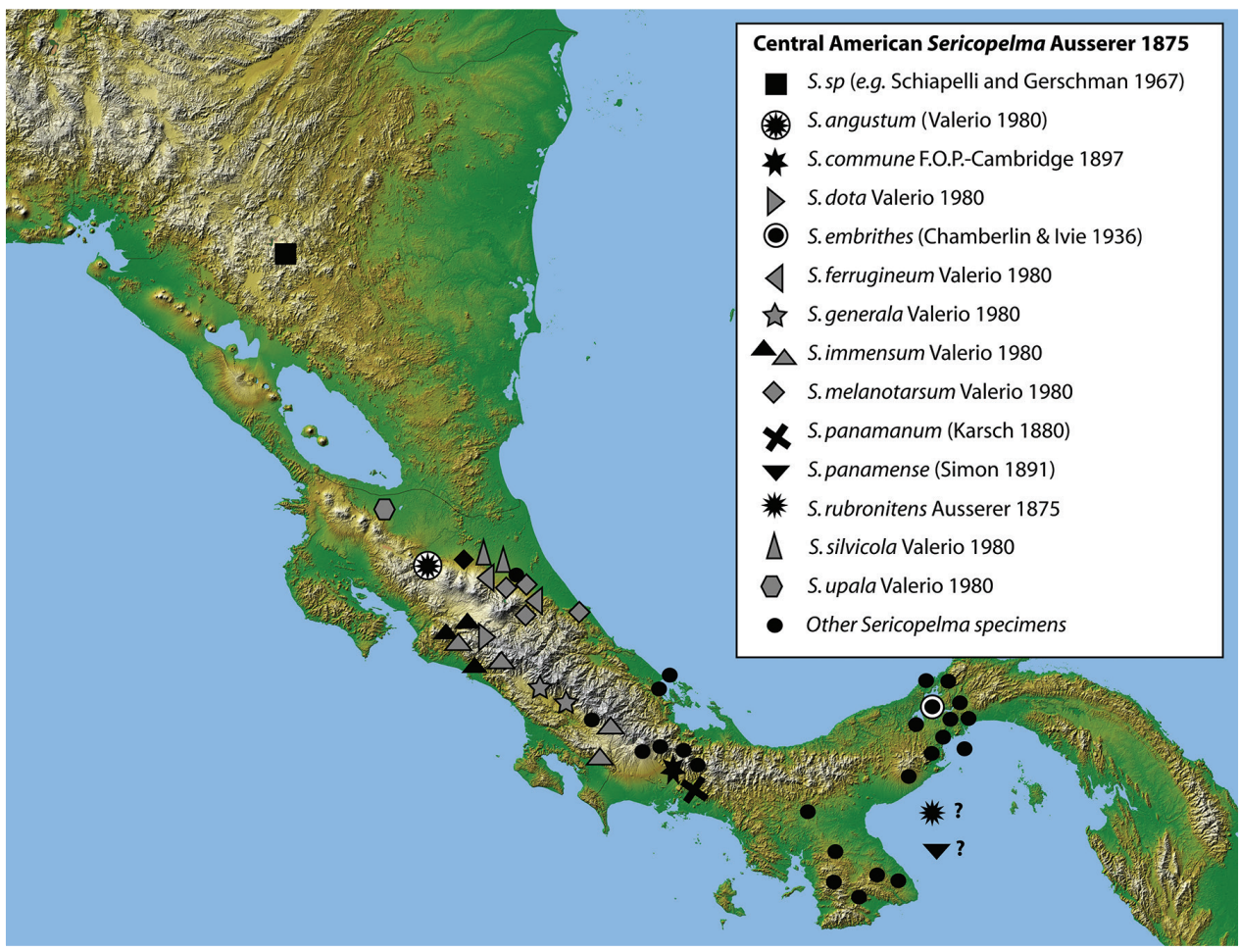

Figure 12. Geographic distribution of the genus Sericopelma from published records (including this study), where complete black-centred shapes are for specimens examined during this study, whilst gray shapes [outlined in black] are further specimens listed by Valerio (1980), accordingly data for S. immensum has black shapes (for the holotype, allotype and further female from Pozo Azul de Pirrís examined here), and gray shapes for further sites of Valerio. S. rubronitens and S. panamense are of unspecific location, but canal-zone seems likely.

$m a$, from Ventanas (leg. Forrer). This is likely modern Villa Corona, Estado Durango $\left(\mathrm{DMS}=23^{\circ} 52^{\prime} 51^{\prime \prime} \mathrm{N}, 105^{\circ} 46^{\prime} 19^{\prime \prime} \mathrm{W}\right)$ (Selander and Vaurie 1962), but concurs both with the route of Seemann (within $15 \mathrm{~km}$ from Mazatlán to Ciudad de Durango) and with modern understanding of the species distribution across Sinaloa, Durango and Nayarit (Locht et al. 1999). Pickard-Cambridge (1897) mentions two males by Mr. Forrer from Ciudad [modern Victoria de Durango] plus Simon's male from Ventanas, but none specifically as neotype. One adult male which Smith (1994) refers to as neotype was accessioned in NHM as BMNH 98-12-24-32 where it is labelled 'leg. Forrer' plus 'Ciudad'. The second adult male is in the Pickard-Cambridge collection at OUNMH (Jar 65), with the same collection details of 'Ciudad. Mex, Forrer', plus labelled 'paratype A.M. Smith'. However, we argue preference could have been given to the generic type of Simon from Ventanas. Simon (1891) also referred to a female specimen, though Pickard-Cambridge (1897) stated the female is unknown. However Smith (1994) gives a comprehensive description of both sexes, using a later 
female BMNH 1962-2-28-1, and as a result the taxonomic identity of this species is clear. Simon (1891) originally emphasized several characters for Brachypelma, including presence of distinct scopula on the metatarsus, and femur IV without inner scopula (i.e. no dense pad of plumose hairs), instead long and simple hairs ("metatarsus paris scopula crassa medium articulum fere attingente munitus, femora postica haud scopulata intus longe et simpliciter pilosa", Simon 1890). The genus is also characterised by plumose hairs on the prolateral face of leg I trochanter/femur and retrolateral face of the palp (Pocock 1903). These features have been supported by subsequent authors as diagnostic for Brachypelma (e.g. Smith 1994), such as both sexes without a plumose pad on leg IV femur, the metatarsus IV distally one-third to one-fifth scopulate, and no tarsal division by stiffened setae, along with male palpal bulb distally wide and flattened (spoon-shaped), two unequal spurs on male tibia of leg I, females with a simple undivided/fused spermathecae (Figs 13-14) which we further clarify have a flat crosssection. Despite some earlier confusion about the types, the type species B. emilia is well defined, and the genus is easily separated from Sericopelma. The geographic range of Brachypelma is securely centred in south-western Mexico, now with B. albopilosum and B. fossorium at its southern-most limit in Northern Costa Rica. Due to the generic transfers here of $S$. angustum and S. embrithes (and comments below on other specimens), there are now no reliable records of the genus Brachypelma in Panama. The transfers proposed here verify that the Brachypelma as currently defined ranges from Mexico to north Costa Rica, and is not native in Panama or further south.

Geographic distribution of Sericopelma. From examination of specimens (see methods and supplement), combined with data we consider reliable in Schiapelli and Gerschman (1967) and Valerio (1980), we consider that Sericopelma ranges from Nicaragua to Panama (Fig. 2), with the northern-most report from Nicaragua. This was confirmed by examination of a single male specimen from Matagalpa, Nicaragua held in MCZ.

We regard the inclusion of 'Guatemala' in the original type locality of S. panamense from 'Panama, Guatemala' as an error, and suggest that 'Guatemala' instead refers to the locality for a second specimen (actually from another genus, and seemingly not of a taxon from Panama) which we found in the same jar from the Paris collection.

Panama [Provincia]: Sericopelma commune Pickard-Cambridge 1897 [Chiriquí]; S. embrithes (Chamberlin \& Ivie, 1936) [Panamá]; S. panamense (Simon 1891) [Unspecified ${ }^{*}$ ]; S. rubronitens Ausserer 1875 [Unspecified**] (including as junior synonym S. panamanum (Karsch 1880) [Chiriquí]). Costa Rica [Provincia]: Sericopelma angustum (Valerio 1980) [Alajuela]; S. dota Valerio 1980 [San José]; S. ferrugineum Valerio 1980 [Cartiago, Heredia]; S. generala Valerio 1980 [San José]; S. immensum Valerio 1980 [San José, Puntarenas]; S. melanotarsum Valerio 1980 [Alajuela, Cartiago, Heredia; Limón]; S. silvicola Valerio 1980 [Cartiago, Heredia, Limón]; S. upala Valerio 1980 [Alajuela, Cartiago]. Nicaragua [Departmento]: Sericopelma sp. indet. [Matagalpa] (e.g. Schiapelli and Gerschman 1967).

Note: The extralimital Brazilian Sericopelma fallax Mello-Leitão, 1923 is considered misplaced (see Gabriel and Longhorn 2011). * Originally listed as Panama and Guatemala, though the latter is unlikely. ${ }^{* *}$ Originally simply listed as Panama. 

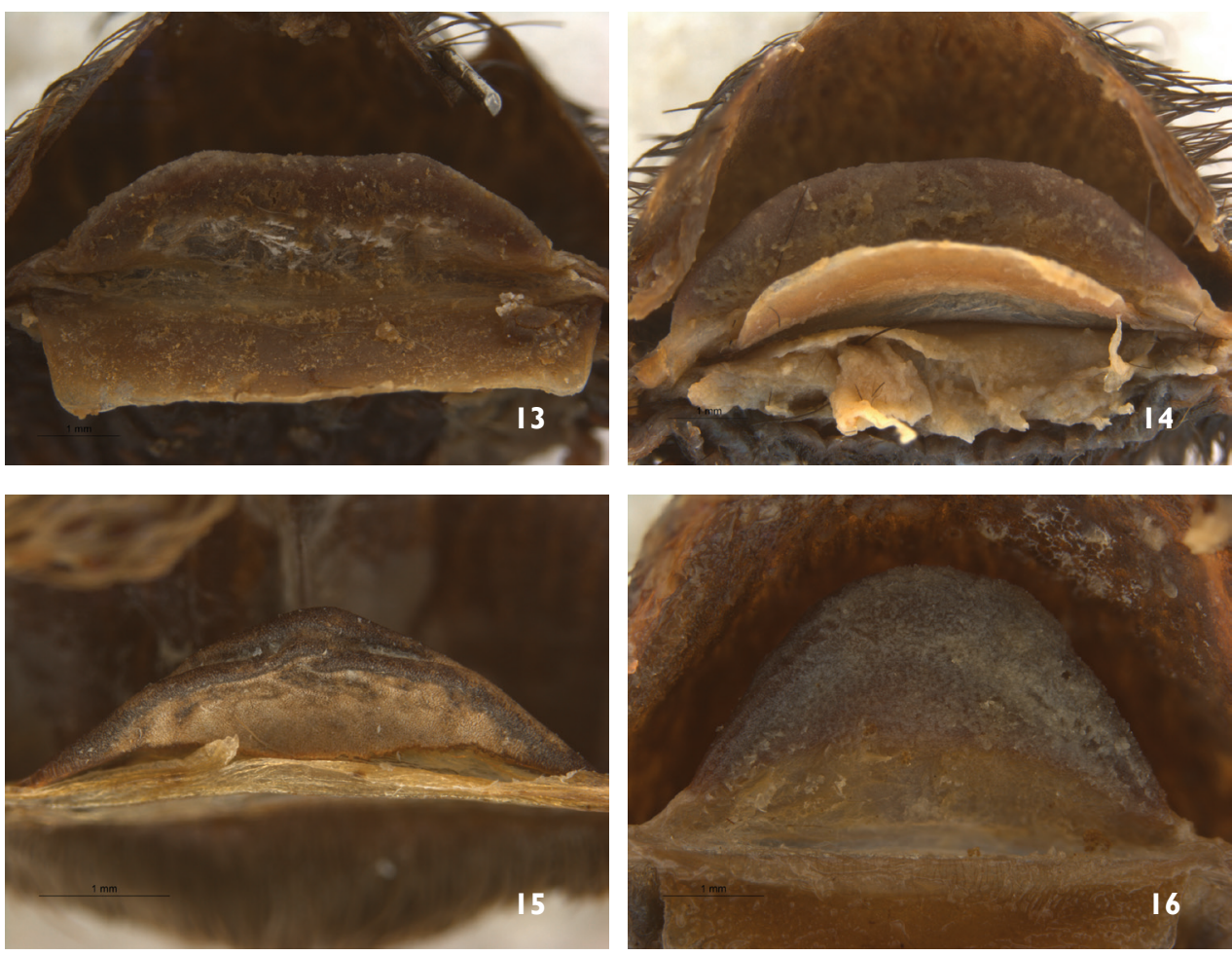

Figure 13-16. Selected taxa with similar spermathecae to Sericopelma. I3 Brachypelma emilia, type species of the genus from México, specimen EME10 in SJLC 14 Brachypelma verdezi from México, PAL4 in SJLC I 5 Megaphobema robustum type species of the genus from Colombia, OUMNH 2008072 (ROB3); and 16 Megaphobema mesomelas from Costa Rica as MES4 in SJLC.

\section{Discussion}

Prior to Valerio (1980) the diagnostic features for Sericopelma were poorly known, with males primarily recognised by the palpal bulb shape and absence of tibial apophyses (Ausserer 1875, Karsch 1880, Simon 1891/82), while females were unrecognized until Schiapelli and Gerschman (1967). Over-reliance on the lack of male tibial apophyses led many museum specimens to be mislabelled and misplaced. In actuality, Simon (1891) had described the first female Sericopelma as Eurypelma panamense, but unrecognized until Gabriel (2009) rediscovered it as a former Eurypelma, a genus that Raven (1985) had described as a taxonomic "dumping ground". We now confirm that Chamberlin and Ivie (1936) misplaced another female into Eurypelma, here transferred to Sericopelma embrithes (Chamberlin \& Ivie, 1936). As the female characteristics of Sericopelma have long been uncertain, the female description by Smith (1991b) was valuable to resolve uncertainty about spermathecae characteristics. Schiapelli and Gerschman (1967) illustrated the first spermatheca of a probable Sericopelma from Nicaragua (Fig. 3) [Nb. specimen not seen]. Their relatively poor illustration shows 
possible indentations or notches on the apex, which appears atypical of the genus. However, we confirm that Sericopelma indeed exists in that region from another examined male Sericopelma sp. in MCZ with the label "Matagalpa, Nicaragua". Valerio (1980) described seven species from Costa Rica, only illustrating the spermathecae of both S. immensum and S. silvicola as simple domes, and neither shows any such notches. Neither do spermathecae of Smith (1991b) nor Schmidt (1994) show any such notches. Perez-Miles et al. (1996) reproduced the Schiapelli and Gerschman (1967) illustration, stating female Sericopelma have "a single spermathecae receptaculum with a median notch", plus key "19. Female with notched spermathecae". Schmidt (2003) also referred to the Sericopelma spermathecae as "Einteilige flache" (i.e. single flat) using the same illustration, not mentioning any apical notches or indentations. We regard the 'notched spermathecae' of Schiapelli and Gerschman (1967) as misleading, and its use to define female Sericopelma as erroneous. We find that mature female Sericopelma spermathecae lack any distinct median notch (Fig. 4) and furthermore, are distinctly swollen on the apex producing a diagnostic P-shape when viewed in profile (Fig. 5), which is also diagnostic for most immature Sericopelma females. We suggest this apical swelling probably expands with age (i.e. ontogenetic modification). Although the holotype spermathecae of $S$. angustum does have a slight medial concaved indentation, we consider this unique. It also shows the diagnostic swollen apex with P-shaped profile diagnostic for Sericopelma. The swollen apex is not found in the other Neotropical theraphosid genera where females have a single unilobar spermathecae, instead flattened or apically narrowed cross-section, such as Brachypelma Simon, 1890, Megaphobema Pocock, 1901 and Theraphosa Thorell, 1870. Female Sericopelma can be distinguished from Eupalaestrus Pocock, 1901, Vitalius Lucas, Silva \& Bertani, 1993, Nhandu Lucas, 1983, Pamphobeteus Pocock, 1901 and Xenesthis Simon, 1891 by the unilobar spermathecae lacking two separated apical projections (Bertani 2001), and from Mygalarachnae Ausserer, 1871, by the unilobar structure lacking a broad median notch (Gabriel and Longhorn 2011).

Along with spermathecae attributes, Sericopelma can now be defined by; Carapace longer than wide (Ausserer 1875, Karsch 1880, Simon 1892, Pickard-Cambridge 1897, Schiapelli and Gerschman 1967), deep transverse fovea (Ausserer 1875, Karsch 1880, Pickard-Cambridge 1897) and distinct radiating sulci (Ausserer 1875). We confirm these attributes as useful for both sexes, although carapace is more rounded in mature males than females. Another useful diagnostic is few/weak metatarsal scopulae on distal leg IV forming two distinct pads, elsewhere defined as "barely a trace of scopula on metatarsus IV" (Chamberlin and Ivie 1936), "not scopulate, or very slightly so at the apex" (Pickard-Cambridge 1897), or absent (Ausserer 1875, Simon 1892, Valerio 1980, Schiapelli and Gerschman 1967). Here we confirm that almost every examined specimen of Sericopelma actually does have trace of scopulae on the distal leg IV metatarsus, most forming two small distinct pads when viewed ventrally (Fig. 17, in most extensive form). Such 'trace scopulae' are typically present on in both mature sexes, but in some specimens are distinct while in others greatly reduced. The fresh specimens that lacked trace scopulae were smaller juveniles, suggesting the feature may become 

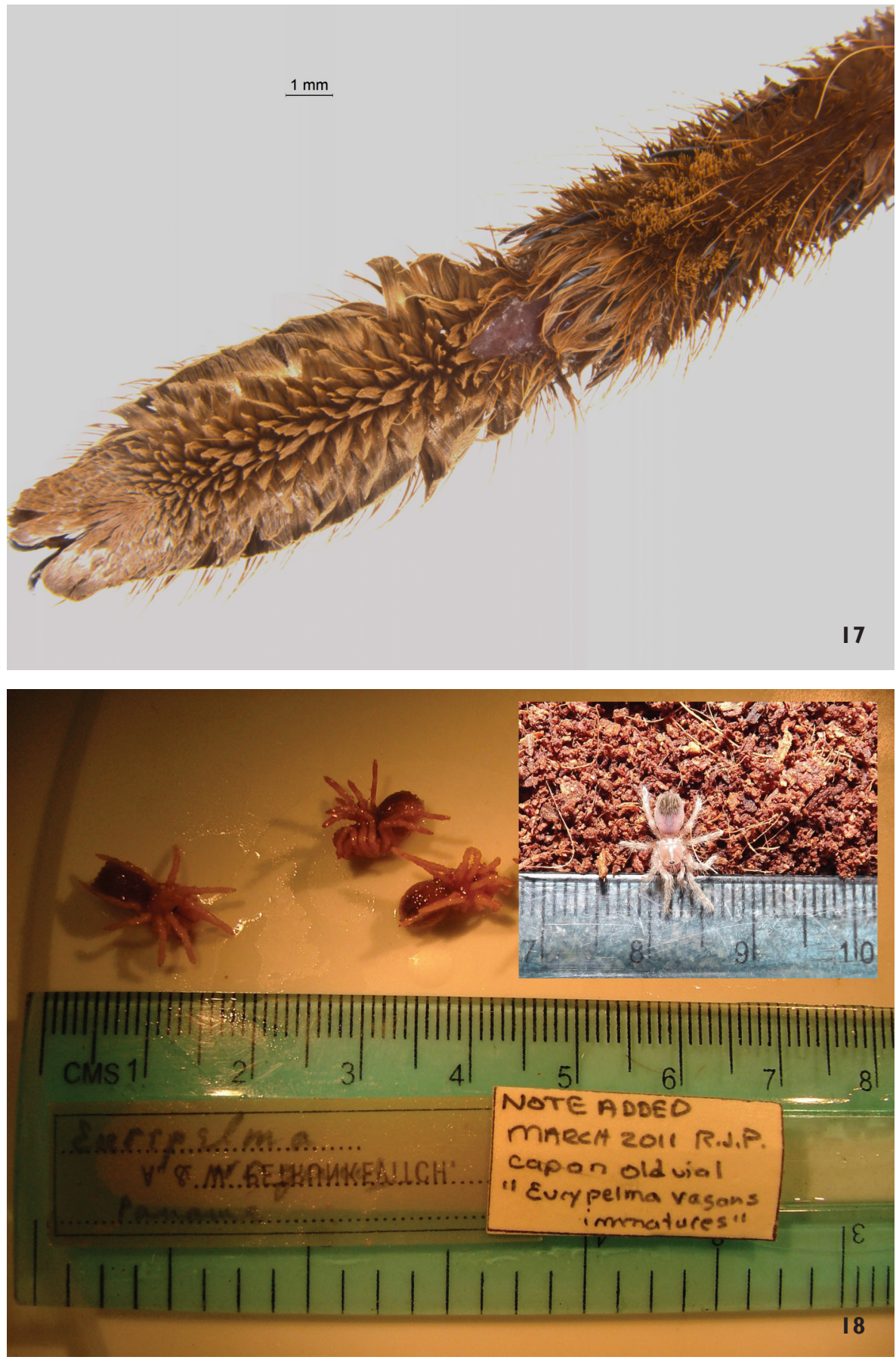

Figure 17-18. 17 Leg IV tarsus and metatarsus of Sericopelma immensum, allotype female (Naranjal de Guarumal, Cantón Puriscal, San José, Costa Rica), showing most extensive metatarsal 'trace' scopula I 8 Nymphal (pre-dispersal) young misidentified by Petrunkevitch as Brachypelma vagans Panama, and inset, older yet smaller (post-dispersal) young of Brachypelma cf. vagans (pettrade, from Mexico). 
more conspicuous through development. Trace scopulae were absent on some larger specimens, but only when eroded through wear or damage. Our examination of $S$. angustum confirmed trace scopulae on leg IV metatarsus as with other Sericopelma, unlike the one-third to one-fifth scopulae present in Brachypelma. From a large array of specimens (see Supplement), female Sericopelma may be robustly defined by: Spermathecae single (unilobar), swollen at the apex to form a P-shaped cross-section, femur IV with a dense retrolateral pad of plumose hair, trochanter/femur of leg I lacking stridulatory setae, carapace longer than wide, deep transverse fovea and distinct radiating sulci, ventral metatarsus IV with a divided and reduced trace of scopulate hairs at the distal end. Apart from spermathecae attributes, these remaining features also define mature males along with the absence of tibial spurs and characteristic embolus shape.

The dense retrolateral pad of plumose hair on femur IV is another useful character to separate Sericopelma from Brachypelma. We clarify the term 'femoral scopula/e' in Sericopelma as a broad pad of plumose hairs. Valerio (1980) defined Brachypelma with "Scopula in femur IV inconspicuous or absent", as did subsequent authors (Smith 1994, Schmidt 2003). Yet Valerio (1980) had previously confirmed that femur IV of $B$. angustum does indeed have a modified patch of hairs, by "Femur IV con cojinete medial' (p. 270), and elsewhere confirmed Sericopelma indeed posses such. Our examination of the $S$. angustum holotype (Figs 6-11) showed a broad pad of plumose hair on retrolateral femur IV (Fig. 10) as in other Sericopelma spp., but not Brachypelma. Schmidt and Krause (1994) reported that Brachypelma klaasi is exceptional with a "thin pad of plumose hairs on femur IV", used to support a new genus Brachypelmides, since rejected. They gave no indication of which sex was examined nor where femoral hairs were found. We therefore also examined mature B. klaasi specimens of both sexes and found no distinct pad on retrolateral femur IV, just a few sporadic fine-hairs slightly plumose basally, near the distal femur. We suggest these conform to the diagnostic 'short weak-feathered hairs (= kurze schwachgefiederte Haare) of Schmidt and Krause (1994), but do not form any distinctive pad as in Sericopelma (as S. angustum and $S$. embrithes). Instead in B. klaasi, these modified hairs are interspersed among more numerous long-fine hairs and thicker bristle-like hairs. Further, there is a baldline forming a longitudinal strip along the axis in B. kladsi, observable in both fresh and alcohol preserved specimens, contrasting with the dense pad of plumose hairs in Sericopelma. Modified hairs of B. klaasi hind-femurs were difficult to distinguish on alcohol-preserved specimens, so we also examined dried exuvia as Schmidt and Krause (1994), where fine-basally plumose hairs were more easily detected. Other examined Brachypelma spp. only showed fine hairs and bristle like hairs on femur IV, as reported for B. albiceps by Locht et al. (1999).

With a more robust definition of Sericopelma (including female characteristics), we can be increasingly certain about generic boundaries. Valerio (1980) defined Sericopel$m a$ by "the presence of a thick scopula in the inner side of femur IV, the absence of spurs on tibia I, [absence of] stridulatory setae on trochanter I, and [absence of] scopula on metatarsus IV". Also "One spermathecae, semicircular, sometimes with lateral extensions, covered with fine spinules", or as "Receptaculum seminis opens on dorsal 
side of apical region, communicating with distal tip of bulb by and open groove." This may be alluding to the apically swollen P-shaped cross-section that we consider diagnostic for Sericopelma. Valerio appears to have been misled by the central depression he characterised as "Spermathecae with a shallow notch in anterior edge (Fig. 7 [his figure 19])", leading him to recognise similarity with B. albopilosum, and misdiagnosing them both as Brachypelma by shared "Spermathecae with a conspicuous depression on the anterior edge". Our examination of $S$. angustum showed the spermathecae indeed possesses a slight medial indentation, but less defined than Valerio suggested, and we further recognise the apical swelling with a P-shape cross-section (Figs 8, 9) as diagnostic of Sericopelma. Spermathecae of other genera like Brachypelma (Figs 13-16) are flat throughout in cross-section. Further, S. angustum does not have any plumose hairs on the prolateral trochanter or femur of leg I (or II), nor the retrolateral palpal trochanter (i.e. Smith 1994, Schmidt 2003), but does have a distinctive pad of plumose hairs on femur IV (Fig. 10), together confirming it as Sericopelma, representing a unique species due in part to distinctive spines on tarsus IV (Fig. 11).

During this study, we found many historical museum specimens with mistaken identities, most importantly several wrongly reported as Panamanian Brachypelma. Petrunkevitch (1925) listed Sericopelma commune, 1 male and 1 female from the Canal zone. Sericopelma rubronitens from 2 females from Culebra (probably Pacific Canal Zone, 'Gaillard Cut'), and 2 females from Bocas del Toro. As discussed above, $S$. commune was described from males collected in distant Chiriquí, hence the identity of his Canal Zone species is dubious. Petrunkevitch did not compare his specimens to the earlier male types (nor could he with females), so his determination of various females as $S$. rubronitens cannot be regarded as reliable descriptions. Our confidence in Petrunkevitch determinations is greatly reduced as he also misidentified other geographically diverse specimens as $S$. rubronitens, all from outside the geographic range of the genus Sericopelma, such as from México, Haiti, and Ecuador (see supplement for re-evaluation), probably as all were similarly coloured with dark bodies and reddish abdominal hairs. He also inconsistently referred to specimens from Barro Colorado Island as either $S$. rubronitens or $S$. commune (see supplement), despite being the type locality for S. embrithes. Petrunkevitch (1925) mistakenly reported several Brachypelma from Panama, namely $B$. emilia, 1 female of $B$. sabulosum from Culebra, 1 female of $B$. vagans from Culebra, plus 4 young $B$. vagans specimens without locality. For $B$. emilia, Petrunkevitch (1925) merely repeated the erroneous location from the original description. Interestingly, some male Sericopelma from Chiriquí do superficially resemble B. emilia by light pinkish lower legs and carapace, plus black triangle on the carapace, perhaps leading to early confusion. On re-examination of the Petrunkevitch specimens in PMY, his alleged B. sabulosum was a Sericopelma sp, as likely are the $4 \mathrm{im}$ matures of alleged $B$. vagans. The immatures are pre-dispersal nymphs, with the wrong proportions for $B$. vagans - where nymphs are almost one fifth of this size. In $B$. vagans, the legs remain proportionally shorter even when older post-dispersal 'spiderlings' of equivalent size (Fig. 18). The most likely genus for these large nymphs is Sericopelma. The alleged female $B$. vagans was not located, but we also expect to be a misidentified 
Sericopelma, which can be similarly coloured and often confused by non-specialists. Distribution of $B$. sabulosum and B. vagans from Panama should be regarded as mistaken, $B$. sabulosum is only validly recorded from Guatemala, whilst $B$. vagans is recorded from México, Belize and Guatemala.

Finally, another allied Costa Rican species with long ambiguous placement is Megaphobema mesomelas (O.P.-Cambridge, 1892), again originally placed in the poorly defined Eurypelma. Valerio (1980) described the first female and transferred it to Brachypelma before Schmidt (1991a/b) transferred to Megaphobema. Smith (1991b) also reevaluated the species, drawing tarsus IV with twin central lines of modified setae (his figure 6), which Valerio had recognised as "Cojinete del tarso IV dividido por varias filas de espinas". Against this, we considered $S$. angustum where scopulae are interspersed by thickened spines (Fig. 11), which we consider species specific - as not observed in other Sericopelma, nor mature specimens of other candidate genera. However, our inspection of various recent (both sexes) and historical specimens of $M$. mesomelas (including the male holotype and another male from same collector in the O.P.-Cambridge collection), each revealed only few long soft hairs on tarsus IV, not thickened spines. Our re-examination of $M$. mesomelas lead us to agree it does not belong in Brachypelma, nor Sericopelma, but neither do we agree with placement in Megaphobema (Gabriel and Longhorn, in prep). Female Sericopelma can be distinguished from Megaphobema by the form of the spermathecae, in the latter by greater ventral surface sculpturation with striated grooves more evenly spaced and extending to lateral edges, or a more cerebriform pattern, plus flatter cross-section (Fig. 15). Mature males of Sericopelma lack tibial apophyses (as do some other genera), but are present in Megaphobema (and other genera). Both sexes of Megaphobema also can be distinguished from Sericopelma by more extensive scopulae on metatarsus IV. For $M$. mesomelas the sternum is especially narrow and elongate, which Smith (1987) says "over twice as long as wide". We agree, observing the $M$. mesomelas sternum is more extremely narrowed than $S$. angustum. The narrowed form in both conflicts with Brachypelma, defined by a broad sternum (i.e. Simon 1891, "Sternum aeque longum ae latum"). S. angustum was diagnosed by Valerio (1980) by "Carapace longer than $18.0 \mathrm{~mm}$ " or "Carapace very narrow (1.6 times longer than broad)", and his specific epithet 'angust' (= narrow) refers to both the narrow cephalothorax and sternum. We suggest the narrowed sternum can be indicative of close evolutionary affinities of $M$. mesomelas with Sericopelma, particularly S. angustum.

\section{Consequences for conservation, including CITES}

Currently, all Brachypelma species are protected by international commercial trade regulation (CITES, Appendix II). Transfer of S. embrithes and S. angustum into Sericopelma means that consequently these species may now only be protected by national wildlife laws. However, there does not appear to be a current need to regulate trade in S. embrithes and S. angustum, so we assert both species should indeed be removed from CITES listing. As with most theraphosids, the major threat appears to be habitat 
destruction. For $S$. angustum, much of its probable habitat in northern Costa Rica has already been disrupted by human activity, often for sugar cane plantations. However, its conservation status within Costa Rica must be urgently evaluated. For S. embrithes, much of its original range was likely destroyed during the damming of the Chagres River for the Panama canal, isolating Barro Colorado Island. A more deserving candidate for CITES regulation is Megaphobema mesomelas; a large brightly coloured species which has regularly been targeted by illegal collection for commercial gain, and traded internationally. We also point out there remains need for continued regulation of all Brachypelma sp. traded as exotic pets, including those in the pet-markets still exchanged under the former name 'Brachypelma angustum', which would retain their CITES protected status under the aegis of Brachypelma sp.

\section{Acknowledgements}

The authors thank Christine Rollard and Elise Ann Leguin (NHMP), Norman Platnick and Louis Sorkin (AMNH), Laura Liebensperger and Gonzalo Giribet (MCZ), Janet Becalonni (BMNH), Diomedes Quintero (MIUP), Oscar Francke and Jorge Mendoza (CNAN), Ignacio Vazquez, Francisco Medina and Arturo Locht (LAAHFC), Gilbert Barrantes, Rita Vargas and Monika Springer (MIUCR), Peter Jaeger (SMF), and Ray Pupedis (PMY) for access to museum collections, arranging loans and allowing examination of material. We thank Sylvia Lucas for general guidance, Peter Myler for help with Latin translation, Don Cameron for formation of taxon names, and Darren J. Mann, Zoë Simmons, Amoret Spooner, James Hogan for access to the Oxford collections and use of the Automontage system (sponsored by the A. McCrae bequest). We thank all the generous tarantula enthusiasts who donated specimens for research (see supplement). We especially thank Eduard Hijmensen and Carlos Viquez for helpful discussion, and Craig McInnes for paper translations. Thanks also to Consejo Nacional de Areas Protegidas (CONAP) in Guatemala for collection permit No.000556 to David Ortiz-Villatoro, and export under CITES No.14772 (298-2008), and staff at ANAM Panama for permits to RG under SE/A-39-04, SE/A-97-04, SE/A-29-06, and SE/A-24-08, Dr Annette Aiello and Orelis Arosemena of STRI for assistance with permit applications. We also thank Andrew Smith, Richard Gallon and Zoltan Lestyan for helpful comments on earlier drafts, thank reviewers for diverse suggestions, and Jeremy Miller for editorial guide.

\section{References}

Andre C, Esche S (2011) Die Gattung Sericopelma: Habitat, Lebensweise, Terrarienhaltung und Nachzucht von Sericopelma melanotarsum Valerio, 1980. Arachne 16: 10-31.

Ausserer A (1871) Beiträge zur Kenntniss der Arachniden-Familie der Territelariae Thorell (MygalidaeAutor).Verhandlungen der kaiserlich-königlichen zoologisch-botanischenGesellschaft. Wien 21: 117-224. 
Ausserer A (1875) Zweiter Beitrag zur Kenntniss der Arachniden-Familie der Territelariae Thorell (Mygalidae Autor). Verhandlungen der kaiserlich-königlichen zoologisch-botanischen Gesellschaft. Wien 25: 125-206.

Bertani R (2001) Revision, cladistic analysis, and zoogeography of Vitalius, Nhandu, and Proshapalopus; with notes on other Theraphosine genera (Araneae, Theraphosidae). Arquivos de Zoologica (São Paulo) 36: 265-356.

Chamberlin RV, Ivie W (1936) New spiders from Mexico and Panama. Bulletin of the University of Utah 27(5): 1-103.

Gabriel R (2009) Notes on the taxonomic placement of Eurypelma guyanum Simon, 1892 and Eurypelma panamense Simon, 1891 (Araneae: Theraphosidae). Journal of the British Tarantula Society 24(3): 87-90.

Gabriel R, Longhorn SJ (2011) Redescription of the holotypes of Mygalarachne [sic] Ausserer 1871 and Harpaxictis Simon (1892) (Araneae: Theraphosidae) with rebuttal of their synonymy with Sericopelma Ausserer 1875. Revista Ibérica de Arachnología 19: 157-165.

Karsch F (1880) Zur Arachniden gattung Theraphosa Walckenaer. Zeitschrift für die gesamten Naturwissenschaften 53: 843-846.

Koch CL (1850) Übersicht des Arachniden systems. Nürnberg, Heft 5, 1-77.

Locht A, Yáñez M, Vázquez I (1999) Distribution and natural history of Mexican species of Brachypelma and Brachypelmides (Theraphosidae, Theraphosinae) with morphological evidence of their synonymy. Journal of Arachnology 27: 196-200.

Lucas SM, Schmidt G, Da Silva Jr PI, Bertani R (1991) Wiederaufstellung der Gattung Sericopelma Ausserer, 1875 Araneida, Theraphosidae, Theraphosinae. Studies on Neotropical Fauna and Environment 26: 229-230. doi: 10.1080/01650529109360856

Peters H-J (2000) Tarantulas of the world: Kleiner Atlas der Vogelspinnen - Band 1. Published by the author, $148 \mathrm{pp}$.

Peters H-J (2003) Tarantulas of the World: Amerika's Vogelspinnen. Published by the author, Wegberg, Germany, 328 pp.

Petrunkevitch A (1925) Arachnida from Panamá. Transactions of the Conneticut Academy of Arts and Sciences 27: 51-248.

Petrunkevitch A (1939) The status of the genus Eurypelma (Order Araneae, Family Theraphosidae). Annals and Magazine of Natural History (11) 4: 561-568. doi: 10.1080/00222933908655402

Perez-Miles F, Lucas SM, Da Silva Jr PI, Bertani R (1996) Systematic revision and cladistic analysis of Theraphosinae (Araneae: Theraphosidae). Mygalomorph 1:33-68.

Pickard-Cambridge O (1891) Arachnida, Araneidea and Opiliones. In: Godman FD, Salvin O (Eds) Biologia Centrali-Americana, Zoology, Volume 1. Taylor and Francis, London.

Pickard-Cambridge FO (1897) Arachnida, Araneidea and Opiliones. In: Godman FD, Salvin O (Eds) Biologia Centrali-Americana, Zoology, Volume 2. Taylor and Francis, London.

Pocock RI (1901) Some new and old genera of S.-American Aviculariidae. Annals and Magazine of Natural History (7) 8: 540-555. doi: 10.1080/03745480109443359

Pocock RI (1903) On some genera and species of South-American Aviculariidae. Annals and Magazine of Natural History (7) 11: 81-115. doi: 10.1080/00222930308678729 
Raven RJ (1985) The spider infraorder Mygalomorphae Araneae: Cladistics and systematics. Bulletin of the American Museum of Natural History 182: 1-180.

Roewer CF (1942) Katalog der Araneae von 1758 bis 1940. Bremen 1: 1-1040.

Schiapelli RD, Gerschman de Pikelin BS (1967) Estudio sistemático comparativo de los géneros Theraphosa Walck., 1805; Lasiodora C. L. Koch, 1851 y Sericopelma Ausserer, 1875 (Araneae, Theraphosidae). Atas do Simpósia sôbre a Biota Amazônica (Zoologica) 5: 481-494.

Schmidt G (1991a) Revision der Gattung Megaphobema (Araneida: Theraphosidae: Theraphosinae). Arachnologischen Anzeiger 13: 11-13.

Schmidt G (1991b) A letter concerning Megaphobema mesomelas and its taxonomic position. Journal of the British Tarantula Society 7(1): 5-6.

Schmidt G (1992) Brachypelma Simon 1890 oder Euathlus Ausserer 1875? (Araneida: Theraphosidae: Theraphosinae). Arachnologischen Anzeiger 3(1): 9-11.

Schmidt G (1993) Vogelspinnen: Vorkommen, Lebensweise, Haltung und Zucht, mit Bestimmungsschlüsseln für alle Gattungen, Vierte Auflage. Landbuch-Verlag GmbH, Hannover, $151 \mathrm{pp}$.

Schmidt G (1994) Das Weibchen von Sericopelma melanotarsum Valerio, 1980. Arachnologische Magazin 2(3): 1-4. doi: doi: 10.1080/01650529409360911

Schmidt G (2003) Die Vogelspinnen, Westarp Wissenschaften-Verlagsgesellschaften mbH, Hohenwarsleben, $381 \mathrm{pp}$.

Schmidt G, Kraus RH (1994) Eine neue Vogelspinnen-spezies aus Mexico, Brachypelmides klaasi sp. n. (Araneida, Theraphosidae, Theraphosinae). Studies on Neotropical Fauna and Environment 29(1): 7-10.

Seemann B (1852) The Botany of the voyage of H.M.S. Herald (etc.), Reeve and Co. Henrietta Street, Covent Garden, London, 483 pp., plus plates.

Selander RB, Vaurie P (1962) A gazetteer to accompany the "Insecta" volumes of the "Biologia Centrali Americana”. American Museum Novitates 2099: 1-70.

Simon E (1891) Liste des espèces de la famille des Aviculariides qui habitent l'Amérique du nord (plus appendice: Liste des Aviculariides qui habitent le Mexique et l'Amérique centrale). Actes de la Société Linnéenne de Bordeaux 44: 307-339. [note: original copy displays 1890 on the cover]

Simon E (1892) Histoire naturelle des araignées. Deuxième édition librairie encyclopédique de Roret, Paris 1: 1-256. doi: 10.5962/bhl.title.51973

Simon E (1903) Histoire naturelle des araignées (Supplement general). Librairie encyclopédique de Roret, Paris 2: 669-1080.

Smith AM (1986) The tarantula: Classification and identification guide. Fitzgerald Publishing, London, $178 \mathrm{pp}$.

Smith AM (1987) Species file - B. mesomelas (Cambridge 1897). Journal of the British Tarantula Society 2 (1): 7-12.

Smith AM (1991a) A revision of the genus Megaphobema Pocock 1901 (Araneida, Theraphosidae; Theraphosinae). Journal of the British Tarantula Society 6 (4): 14-19.

Smith AM (1991b) Discussion paper: Euathlus mesomelas Cambridge 1892. Journal of the British Tarantula Society 7(2): 15-23.

Smith AM (1994) Tarantula spiders of the U.S.A. and Mexico. Fitzgerald Publishing, London, 196 pp. 
Valerio CE (1980) Arañas terafosidas de Costa Rica Araneae, Theraphosidae. I. Sericopelma y Brachypelma. Brenesia 18: 259-28.

Vogel BR (1969) Spider types at Yale Peabody Museum. Published privately by the author, Austin, Texas, 14 pp. [available on request]

West RC (2005) The Brachypelma of Mexico. Journal of the British Tarantula Society 20(4): 108-119.

White A (1856) Description of Mygale Emilia, a spider from Panama, hitherto apparently unrecorded. Proceedings of the Zoological Society London 1856: 183-185. [Reprinted in 1857, Annals and Magazine of Natural History 19(2): 406-407.]

World Spider Catalog (2015) World Spider Catalog. Natural History Museum Bern. http:// wsc.nmbe.ch [Version 16.5 accessed on July, 2015]

\section{Appendix}

Additional non-type material for comparison. Note - SJLC are mainly pet-trade, often of unclear providence unless otherwise stated, plus exuvia of other immatures and adults]

\section{Sericopelma specimens:}

S. embrithes [Panama, Canal zone = Prov. Colón, Panamá and Panamá Oeste] - MCZ: 2 + 2 Imm, Sericopelma embrithes 74344 July 1936, B.C.I; 1 Imm ôS. embrithes 74335 22/10/1954 B.C.I; 1 Imm đ̊ S. embrithes 74637 20/10/1950

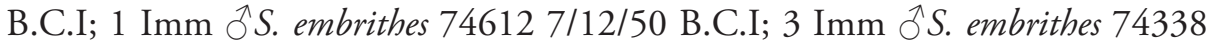
B.C.I; 2 Imm $\lesssim S$. embrithes 74345 June - July 1950, B.C.I; 1 Imm $\lesssim S$. embrithes 74634 23/07/1950, B.C.I; 1 Imm ở S. embrithes 74348 06/08/39, B.C.I; 7 Imm S. embrithes unsexed, 74340 16/08/1954, B.C.I; $1 \mathrm{Imm}+1 \mathrm{Imm}{ }^{\lambda} S$. embrithes 74343 B.C.I; 2 Imm § 3 Imm q S. embrithes 74342 July 1936 B.C.I; 1 Imm o $S$. embrithes 74635 summer 1939 B.C.I; 1 Imm ổ S. embrithes 74336 summer 1939, B.C.I; 1 9 74373, [no data], 1 Imm đ̋ S. embrithes B.C.I., Canal Zone, Sept, coll. Phil Raw; PMY: 1 q S. embrithes B.C.I. Canal Zone, Panama, July 1938, Coll. and Ident. (as S. rubronitens) by A. Petrunkevitch, from burrows on the lawn by the laboratory; 2 q S. embrithes B.C.I. Panama, 04.viii.1938. coll. and Ident. (as $S$. rubronitens) by A. Petrunkevitch, [reverse reads 'in life with red abdomen]; $1 \mathrm{Imm}$ T S. embrithes (as S. rubronitens) B.C.I. Panama, July 1938, Coll. and Ident. by A. Petrunkevitch [mis-sexed + ]; 1 đ S. embrithes B.C.I. Canal Zone, Panama, Coll. and Ident. (as S. communis) by A. Petrunkevitch, $1 \mathrm{Imm} \widehat{\delta}$ S. embrithes B.C.I. Panama, July 1938, coll. and Ident. by A. Petrunkevitch, [mis-sexed as + ];1 $q 4$ larvae S. embrithes 7 Imm, B.C.I., Canal Zone, A.M. Chickering, $195 \mathrm{imm} S$. embrithes, B.C.I., Canal Zone, A.M. Chickering, July 121934.

Sericopelma spp. [Panama, Canal zone = Prov. Colón, Panamá and Panamá Oeste] - BMNH: 1 O Sericopelma sp. 1926.1.27.14 Taboga Island, Panama, 12/09/24, coll. G.I. Collenette. MCZ: 1 Imm $q 2$ Imm đ̂̉ Sericopelma sp. 74341 Ft. Clayton, IPAC. Side Panama, coll. Shropshire; 1 đ Sericopelma sp. 74346 Fort Davis, C.Z. 1924-1925 coll. Major D.R. Chase; 1 đ Sericopelma sp.74638 Bouia Point 1927, 
J. Barbour Don, I.B. Shropshire, collection; 1 q Sericopelma sp. Fort Sherman C. Z. [Canal Zone], Feb 1924, det, N. Banks; 2 ○ Sericopelma sp. Ancón, Canal Zone, Mar-April 1922, T. Barbour and W.J. Brooks, det, N. Banks; 1 † 2 ઈ Sericopelma sp. Corogae, Canal Zone, Atl.[Atlantic] Side, det. N. Banks. MUIP: 1 万 Sericopelma sp. Panama, Province Panama, Arraijan, San Jose de Bernardino 26.08.2003 coll. M. Barahona; 1 đ̂ Sericopelma sp. Arraijan Panama 08.1995; 2 o $1 \mathrm{Imm}$ ô Vista Bella, Arraijan Panama Rep Panama 08041990 coll. David Maruaga; 2 ô Sericopelma sp. Huili Arraijan, Panama R.D. Pan 8 November 86 coll. Daniel Holnes; 1 q Sericopelma sp. Villalobos, Pedregal. Panama R.D. Pan 05.09.85 coll. Ramito Pinzon, Diana Moreno; 1 đ Sericopelma sp. Imprenta de la Universidad de Panama. Panamá 17.08.1981 coll. H. Martinez; 1 đ̂ Sericopelma sp. Ciudad Panama, Republic de Panama, 26.08.1988 coll. Jasmin (sec. esc) Fistica; 1 đ Sericopelma sp. Panamá province, Panama Campana, L. Ortega 12.09.02; 1 đ Sericopelma sp. Profomsamilla 13, via Bolivar Panama 16 Oct 1980 coll. Alfonso Chong; 1 + Sericopelma sp. Samaria, San Miguelito, Province Panama, Republic of Panama, coll. R. Navarro 16.12.94; 1 ○ Sericopelma sp. Ciudad de Panama, Province Panama, Puerto Nuevo, Republic of Panama, 17.Dic.1977, coll. D. Quintero jnr; 1 ○े Sericopelma sp. Isla Bagano, near bridge wet more, on forest litter, Province Panama, Republic of Panama, 31.01.76, coll. Claudia de Peralta; 1 ô Sericopelma sp. Province Panamá, Chilibre Carretera Puente de Chilibre, 25m despues del Puente, 15.Oct.1977, coll. D. Quintero jnr; 1 ô Sericopelma sp. Ciudad de Panama Ivan Diaz de rajo de tronco caido, Republic of Panama, 09.Dec.1977, coll. D. Quintero jnr; 1 q Sericopelma sp. Panama, Province Panamá, area del canal, Howard Hecia Ferfan, 7-8.Feb. 2009, coll. S. Ortaga; 1 ㅇ Sericopelma sp. Republic of Panama, Panamá Oeste Province, Bejuco, Sora, 21.Julio. 2007, coll. R. Carranzo. PMY: 1 q Sericopelma sp. Culebra, Panama [was misidentified as B. sabulosum]; 4 Imm Sericopelma sp. Panama, [were misidentified as B. vagans], 1 + Sericopelma sp. Culebra, Panama (described as S. rubronitens in the "Arachnida of Panama"), A. Petrunkevitch; $1 \mathrm{Imm} \delta$ S. cf. rubronitens Culebra, Panama; 1 O S. cf. rubronitens Culebra, Panama, Dr. B.H. Buxton. [Panama, Central zone = Prov. Coclé, Herrera, Los Santos, Veraguas] - MCZ: 1 त Sericopelma sp. El Valle, Panama, August 1936 (likely El Valle de Antón, Coclé; 1 o 1 O Sericopelma sp. 74371, San Pablo, Panama, Serly (possibly Rio San Pablo, Soná). MUIP: 1 đิ Sericopelma sp. Altos de El Valle, Finca el Naranjal, Panama (Coclé), 22 Julio 1979, coll. Elisa De Fuentes; 2 o Sericopelma sp. Rio Hato as Pollas Clano Bonito, Farallon el Plastanoc, Las Guias y El Rincon, Coclé, Panama 10.6.85, 24.7.85; 1 o Sericopelma sp. Panama, Province Coclé, Río Hato (Las Guias - Farallon), Sept - Oct 1983, coll. A. Parra; 1 Imm $q$ Sericopelma sp. Panama, Province Herrera, District Las Minas, R.F. [=Refugio Forestal] El Monteuso Estacion,13-15.Dic 2002 coll. P. Gonzales; 2 + Sericopelma sp. Panama, Province Herrera, R.F. El Montueso, 3 Mayo 2007, coll. R.J. Miranda \& A. Santor; 2 đ Sericopelma sp. Theraphosidae S. commune F.O.P.C. 1897 Det R.J. Miranda 2004 
Panama, Province Los Santos, Cerro Canajagua 830m alt 11.12.02 coll. D. Gonzalez; 1 đ Sericopelma sp. Panama, Prov. Los Santos, Honantial 19. Augusto. 2000 L. Shamix; 1 O Sericopelma sp. Panama, Province Herrera, San José, Oct 24 de Leo 1989, coll. K.F. Ponce; 1 + Sericopelma sp. Panama Province Los Santos, R.F. La Trondsa, La Trondsa, 14-17 Augusto 2007, coll. R.J. Miranda. 1 đ Sericopelma sp. San Juan, Rio Cańazas, Province Veraguas, Panama, 22.Agusto.1987, coll. D. Quintero. [Panama, West Zone = Prov. Chiriquí, Bocas del Toro] - MCZ: 1 i 74632 Boquete R.P. 23.03.1941; 1 P Sericopelma sp. Panama, Chiriquí, Volcán, 1200m el [elevation], 9/viii/1983, H.+L. Levi, in hole in low stone wall. MUIP: 1 ô Sericopelma sp. Finca del las Flores/Fleurs, Boquete Chiriquí Prov. Panama 07 Junio 1968 coll. Jorge Tovan; 1 ô Sericopelma sp. Boquete, Chiriquí Provence Panama 21.07.1992, coll. Miguel Bogante; 1 q Sericopelma sp. Nueva California, Volcan, Chiriqui Province Republic of Panama coll. Leonardo Yanguez, Ríos de Unas Matas de Caña? debajo de las hojas secas suelo humedo; $1 \mathrm{Imm}{ }^{\widehat{\partial}}$ Sericopelma sp. Isla Colon Bocas del Toro Province, Panama 24.10.82 coll Astenid Araiz; 1 q Sericopelma sp. Volcán, Province Chiriquí, Republic of Panama, 9.Sept.1987, coll. Arsenio Araug; 1 + Sericopelma sp. Isla Taboga, Republic of Panama, Augusto 1985, coll. Kyle Summers. OUMNH: 1 đ̊ S. commune Panama, Jar 106 Chiriquí, Champion, syntype. [Panamá, Unknown Prov.] - MNHN: 1 ○े Sericopelma rubronitens Ausserer 1875. (Simon det) AR4803 PARIS. MCZ: 1 ○ Sericopelma sp.74369, Panama; 2 S Sericopelma sp. 74370, Prob[ably] Panama; 1 ㅇ 1 Imm Ō Sericopelma sp. 74372, Panama.. MUIP: 1 đ Sericopelma sp. Panama 06.12.02 coll. G. Lover; 1 ○े Sericopelma sp. [labeled Theraphosidae] Mulio 9 de Mayo 1994, ?Estuooeucauterisis, Disele el 15 Sept 1993 total 176 dias; 1 o No Data, Panama; $1 \mathrm{Imm}$ ô Sericopelma sp. San Cristobal ?Verani(S) Sanmig Velito Panama, 10.05.93; 1 đ Sericopelma sp. Poblado ?Irhe en la Hibrochet, de Banyo 10.00am, Panama, Republic of Panama, 29.12.88 coll. Abraham Beauville.. OUMNH: 1 q Sericopelma sp. Panama, Jar 82 S. Tinter, Roger, O.P. Cambridge coll. [Unknown - likely Panama]: 1 O Sericopelma sp. Central America ex London Zoo. [Costa Rica] - BMNH: 1 q Sericopelma sp. 1906.11.3.1, Banana River 15 miles from Coast, July 1905, Costa Rica, Jose (?Río Banano, Cantón Limón, Prov. Limón]; 1 q Sericopelma sp. 98-12-24-22 Pozo Azul de Pirrís, Prov. San José, Costa Rica, coll. C. Zeledon [Modern Cantón Parrita, Prov. Puntarenas]; OUMNH: 1 đ Sericopelma sp. Guápiles, Pococi, Prov. Limón, Costa Rica. coll. 2006 Viteslav Honsa SERGU1, died n.11.10, ex Benoit Menart; 1 ㅇ Sericopelma sp. Sabanilla, Puntarenas Sud, Coto Brus, Costa Rica Coll. 2006 leg. Viteslav

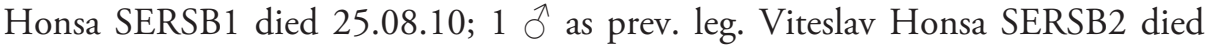
n.11.10, ex Benoit Menart; 1 ठิ S. immensum 2009 007, pet trade, K Matzen, 1 q Sericopelma sp. 2009 007, Costa Rica, ex pet trade w/c 1997; 1 Ô S. melanotarsum 2009 007, ex pet trade, K Matzen; 1 \& S. melanotarsum 2009 007, Costa Rica, w/c died 2000, donated anon. [Nicaragua] - MCZ: 1 ก Sericopelma sp. 74625 Matagalpa Nicaragua 1073, Richardson Dec 1907, R.C. Feb 12-1909. 


\section{Brachypelma specimens:}

B. albiceps - BMNH: 1 \& B. albiceps (CB from German import as B. ruhnaui) RUHZ, died VIII.03, Ex E. Hijmensen/ S. Longhorn. CNAN: 1 ô B. albiceps n79. Teloloapan, Mpio. de Teloloapan. Edo. Guerrero, México. 15.IX.52, coll. Leonila Vazquez; 1 Ò B. albiceps Presa Vicente Guerrero, Edo. Guerrero, México.

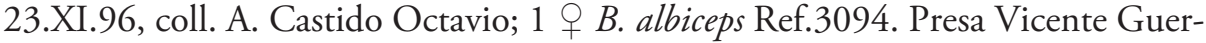
rero, Edo. Guerrero, México. 5.X.76. coll. No data. LAAHFC: 1 ô Brachypelma albiceps Sur Morelos. Edo. Morelos 1996. coll. A. Locht. SJLC [all pet-trade of unknown providence unless otherwise stated]: 1 Imm Brachypelma albiceps RUH2, died 11.IV.09, Ex unknown; 1 § B. albiceps RUH3, died 2008, Ex Mark Davies.

B. auratum - BMNH: 1 + B. auratum Ref.27. Entre Hermiltepec y Río Pungarancho, Edo. Guerrero, México. 02.XI.2002. coll. E. Gonzalez y C. Duran. OUMNH: 49 B. auratum 2007064 pet trade, Lee Arden (spidershop UK) died 2007. SJLC: 1 B . auratum AUR7 died 11.V.08, Ex unknown; 1 \& B. auratum AUR9, died VI.03, Ex Paul Herbert; $1 \hat{\jmath}$ B. auratum AUR10, died I.04, Ex Stephen Copley; 1 ô B. auratum AUR11, died VI.04, Ex Ian Metcalfe; $1 \hat{O}$ B. auratum AUR12, died 25.VI.08, Ex Andy Fischer; 1 o 1 \& B. auratum AUR13/AUR14, died 2008, Ex Mike Fletcher; 1 O B. auratum AUR15, died 2010, Ex Becky Norris.

B. albopilosum-OUMNH: 1 ㅇ B. albopilosum 2007 064, pet trade, C/B. MCZ: 2 ㅇ B. cf. albopilosum 74614, Georgia Fruit Company, Honduras, 20.v.1932; 1 \& B. cf. albopilosum, 74624, With Fruit Honduras; 1 + B. cf. albopilosum 74615, Leon River Valley, East of Río Ulúa, Honduras, 1924, Donor, United Fruit Company, 1 B. cf. albopilosum Río Ulúa, Tela, Honduras, Fruit Company. SJLC: 1 O B. cf. albopilosum ALB1, died 17.II.01, Ex Ronald Baxter; 1 ○ B. cf. albopilosum ALB9, died 03.V.01, Ex Mark Dean; 1 o B. cf. albopilosum died 01.XII.07, Ex Stuart Longhorn CB; 1 o B. cf. albopilosum ALB12, died V.08, Ex Andy Matthews. (Plus several further specimens collected across Honduras to be detailed elsewhere).

B. baumgarteni - OUMNH: 1 B. baumgarteni 2007064 pet trade, Ex Boris Striffler from first import; $1 \hat{\jmath}$ B. baumgarteni 2007 064, pet trade, Ex Boris Striffler from first import - remains of male eaten by female. SJLC: $1 \mathrm{imm} \mathrm{B.} \mathrm{baumgarteni}$

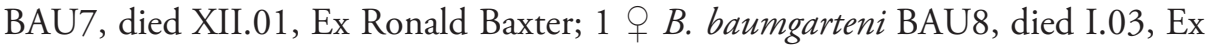
Ronald Baxter; 1 q B. baumgarteni BAU12, died V.08, Ex Paul Herbert; 1 đ BAU13, died 2008, Ex Mark Pennell. Known hybrid - 1 Oे imm B. sp. baumgarteni $\times$ boehmei, BAU10, died 2008, Ex Eddy Hijmensen.

B. boehmei-SJLC: $1 \curvearrowright$ B. boehmei BOH9, died 16.X.03, Ex Ronald Baxter; 1 우 B. boehmei BOH10, died 07.VI.12, Ex Ronald Baxter; 1 § B. boehmei BOH11, died 25.V.08, Ex Mark Kent; 1 ○ B. boehmei BOH12, died 2001, Ex Mark Dean; 1 imm ô B. boehmei BO13, died 2004, Ex Ray Gabriel.

B. emilia - CNAN: 1 + B. emilia Ref.3121. Sinaloa, Edo. Sinaloa, México. 30.I.65, coll. Ent 46; 1 ㅇ B. emilia Ref.3080/No.80. Mazatlán, Mpio. Mazatlán, Edo. Sinaloa, México. VII.1959. coll. Ent 5. OUMNH: 2 + B. emilia 2007 064, pet trade, imported Lee Arden Spidershop UK died 2007; $1 \hat{\jmath} 2007$ 064, B. emilia,

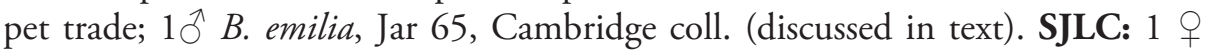


B. emilia EME8, died 12.08.09; 1 ○ B. emilia EME9, died 26.04.09, Ex Andy

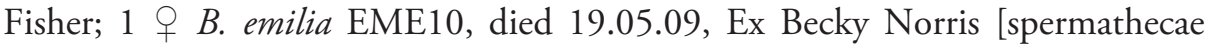
shown in figure 13]; 1 ○ B. emilia EME11, died 2009, Ex Becky Norris; 1 imm, B. emilia EME12, died 2009, Ex Becky Norris.

B. klaasi-CNAN: 1 đ B. klaasi. Reserva Biosfera Chamela - Cuixmala. Edo. Jalisco, México. 18.V.81. coll. A. Pescador. LAAHFC: 1 ô B. klaasi Ref.1714.23 Reserva Biosfera Chamela - Cuixmala. Edo. Jalisco, México. 3.IV.98. coll. A. Locht.

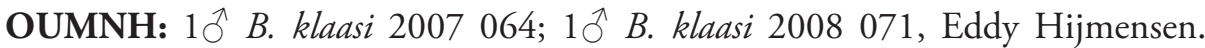
SJLC: 1 đ $B$. klaasi KLA1, died IV.01, Ex Mark Pennell; 1 đ B. klaasi KLA4, died 08.XII.98, Ex Ray Gabriel; 1 o B. klaasi KLA5, died 2002; 1 \& B. klaasi died 2005, Ex Paul Herbert, 1 imm, B. klaasi died 2009, Ex Becky Norris; 1 q B. klaasi died 20.II.10, Ex Mark Pennell.

B. schroederi - SJLC: 1 § B. schroederi SHR3, died VII.08, Ex Steffan Schroeder; 1 ๙ B. schroederi SHR4, died 01.I.10, Ex Andy Hood; 1 त B. schroederi, SHR6, died 20.IX.15, Ex Peter Roach; 1 \& B. cf. schroederi, SHR5, died 19.V.09, Ex James Box.

B. aff. 'smithi' - CNAN: 1 \& B. aff. smithi Entre Tepames y Rio Coahuayana, Frontera, Edo. Colima, México. 8.VII.2005, coll A. Cervantes y M. Olson. LAAHFC: $1 \widehat{\delta}$ B. aff. smithi Colima. Edo. Colima, México. 23.Oct. coll. A. Locht; 1 đ B. smithi Acapulco, Mpio. Acapulco de Juárez, Edo. Guerrero, México. 20.III.97. coll. A. Locht. OUMNH: $1 ð$ B. aff. smithi, 2007 064, C/B, $1 \overbrace{}^{\lambda}$ B. aff. smithi 2009 001, pet trade, 24/09/08, Yinnon Dolev; SJLC: 1 + $B$. cf. smithi (traded as annitha), ANN1, died 25.III.02, Ex Tony Packer C/B; 1 Imm B. cf. smithi (traded as annitha) ANN2, died 2004, Ex Eddy Hijmensen C/B; 1 O B. cf. smithi (trade as annitha), ANN3, died 2007, Ex Eddy Hijmensen C/B; 1 ô B. aff. smithi SMI1, died IV.01, ex Jean-Michel Verdez; 1 ○ B. aff. smithi SMI8, died 03.V.07, Ex Stuart Longhorn; 1 ठ B. aff. smithi SMI13, died unk.II.02, Ex Alan Smith; 1 ठ $B$. aff. smithi SMI16, died 2008, Ex Ray Gabriel; 1 ○ B. aff. smithi SMI17, died 2008, Ex anon; 1 ô B. aff. smithi SMI18, died 18.V.11, Ex Nicola Dolby; 1 \& $B$. aff. smithi SMI9, died 31.I.15, Ex Stuart Longhorn; 1 \& B. aff. smithi SMI12, died X.01, Ex Paul Herbert; 1 imm B. aff. smithi SMI14, died 2004, Ex Ray Gabriel; $1 \mathrm{imm}$ B. aff. smithi SMI15, died 20.07.07, ex Lee Arden; 1 ○ B. aff. smithi $\times$ (?) klaasi hybrid, HYBAXB, died II.10, Ex S.Longhorn.

B. aff. 'vagans' - BMNH: 1 $B$. sp (vagans-complex) 2003-148 Las Cuevas Research Station. Chiquibul National Park, Cayo District, Belize. 27.05.01. leg. Stuart Longhorn, Julie Chuter, Martin Nicholas. 1 ㅇ B. sp (vagans-complex), 2003-148 Pooks Hill Lodge, near Teakettle, Cayo District, Belize, 05.06.01, leg. Stuart Longhorn, Julie Chuter, Martin Nicholas. Plus several other specimens to be detailed elsewhere. CNAN: 1 O B. cf. vagans Celestún, Edo. Yucatán, México. 26.X.00. coll. Tila M.P; 1 ○ B. sp. (vagans-complex) Valerio Trujano, Mpio. Cuicatlan, Edo. Oaxaca, México. 31.XII.04. coll. B. Chavez; 1 đ B. sp. (vagans-complex) Sierra de Sta. Martha. Los Tuxtlas. Edo. Veracruz, México. 17-XII-76. coll. H. Perez; 1 \& B. sp. (vagans-complex) Área Protegida del Selva Lacandona, Mpio. Ocosingo, México. 7-IV-05. coll. O. Francke, A. Ballesteros, A. Valdez; 2 O B. sp. (vagans-com- 
plex) Locale as previous. 6.VIII.2005. coll. As previous. MCZ: 1 q Brachypelma sp. (vagans-complex) 74611, Stann Creek, Belize, under rock, 26.vi.1975, W. Sedgewick. $4 \mathrm{Imm}$ B. sp. (vagans-complex) 74627, El Cayo, British Honduras [Belize], under rock, Feb.-Mar. 1931; 1 क 3 Imm B. sp. (vagans-complex) 74620, Uaxactun, Petén, Guatemala, Mar.-April 1931, H.H. Bartlett. LAAHFC: 1 q Brachypelma sp. (vagans-complex), Los Tuxtlas. Edo. Veracruz, México. No data. coll Unknown; 1 ô Brachypelma cf. vagans Merida, Edo. Yucatán, México. XI.1996. coll. H. Lopez; 1 ô Brachypelma sp. (vagans-complex) Playa el Arroyito. Mpio. Santa María de Huatulco, Edo. Oaxaca, México. 28.XII.98. coll. A. Locht. OUMNH: 1 q Brachypelma sp. (vagans-complex) 2007 064; 1 ㅇ imm Brachypelma sp, Jar 61 1905, Cambridge coll; 1 I Imm Brachypelma sp., Cambridge coll, 1 + Brachypelma sp., "Honduras", Jar 63 Boston* Nr Belize, O. Pickard-Cambridge colln (perhaps New Boston); $1 \delta^{\lambda}$ B. aff. vagans 2007 064, pet trade, C/B; 1 \% B. aff. vagans 2008 071, pet trade, C/B; 1 तै \& 1 ㅇ B. vagans, Jar 69 Guatemala, Cahabón, F. Sarg, Cambridge coll. PMY: 2 + Brachypelma sp. (vagans-group), Tampico, México, Bis;hop Coll. 1940, in life with red abdomen, colour fades before moulting [were misidentified as $S$. rubronitens]. SJLC: 1 \& B. sp. 'sabulosum', Aldea El Remate (casa Don David), nr Flores, Petén, Guatemala. Collected 19.V.08, David Ortiz; 1 đ B. sp. 'sabulosum', SAB1, died VII.03; $1 \curvearrowright$ B. sp. 'sabulosum', SAB2, died 01.III.08, Ex Guatemala, Ronald Baxter; 1 \& B. sp. 'sabulosum', SAB3, died 12.VI.11, Ex Guatemala, Ronald Baxter; 1 + B. cf. sabulosum Parque Nacional Yaxha, Petén, Guatemala, 21.V.08. Coll. David Ortiz and Eduard Hijmensen; 1 \& Brachypelma sp. 'vagans' VAG3, died 25.XI.00; 1 ○े B. sp. 'vagans', VAG4, died VII.01; 1 तै B. sp. 'vagans'VAG7, died 13.VIII.97, Ex Richard Gallon; 1 ^ B. sp. 'vagans' died pre 2001, Ex Richard Gallon; 1 B. albopilosum $\times$ B. 'vagans' (maternally purebred albopilosum) HYB4, died 2005, Ex S. Longhorn; 1 đ B. sp. 'angustum' ANG2, died III.01, Ex Tony Davies; $1 \hat{\sigma}$ B. sp. 'angustum' ANG3, died VI.01, Ex unknown; 1 ㅇ B. sp. 'angustum' ANG4, died 2003, Ex unknown; 1 \% B. sp. 'angustum' ANG5, died 2004, Ex

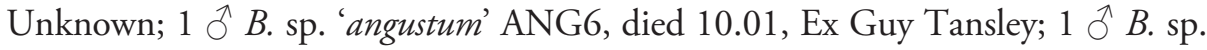
'angustum', ANG7, died 20.X.04, Ex Unknown.

B. verdezi-LAAHFC: 1 + B. verdezi (labelled B. vagans) Acapulco, Mpio. Acapulco de Juárez, Edo. Guerrero, México. 1990. coll A. Locht,. SJLC: 1 \& B. verdezi (traded as pallidum), PAL2, died 2005; 1 \& B. verdezi (traded as pallidum), PAL4, died 26.X.09, Ex David James [see fig. 14]; 1 ก B. verdezi PAL5, died 27.IV.09, 1 đB. verdezi PAL6, died 24.09.08, Ex Yinnon Dolev.

\section{Megaphobema specimens:}

M. mesomelas - BMNH: 2 o M. mesomelas (18)96.3.20.3-4, El Azahar, (Canton Cartago, Dept.) Cartago, Costa Rica. J.F. Tristán (Museo Nacional de Costa Rica). 1 đิ M. mesomelas 1898.12.24.56, La Palma (Prov. Cartago), Costa Rica. J.F. Tristán (Museo Nacional de Costa Rica). [note, this specimen was mislisted as type by Smith 1991b, also has additional label 'Visto por de Pikelin y Schiapelli, mayo 1968’); 1 M. mesomelas (18)96.10.25.1 La Palma (Prov. Cartago), Costa Rica. 
[incl. dissected spermathecae labeled A.M.Smith]; 2 o M. mesomelas 1905.3.29.1415, Cariblanco (San Carlos, Prov. Alajuela), Costa Rica. Charles H. Lankester [both ex dried/pinned]; 2 § M. mesomelas Dried/pinned collection (possibly additional specimens from H. Rogers, Caché listed by FOPC 1897, Costa rica). OUMNH: 1 $\checkmark$ M. mesomelas O. Pickard-Cambridge coll, Dried - drawer 46, Costa Rica (possibly syntype examined by FOPC); 2 + Megaphobema mesomelas 2007 064, pet trade, Eddy Hijmensen; 1 + M. mesomelas 2009 001, Costa Rica, Dutch Pet trade; 1 ô M. mesomelas 2009 001, Costa Rica, pet trade; 1 đ M. mesomelas 2008 072, Costa Rica, 01/12/97, w/c. SJLC: 1 + M. mesomelas MES4, died 12.12.01 [see fig. 16].

M. peterklaasi-OUMNH: 1 + M. peterklaasi 2008 072, pet trade, Ex A Mathews; $1{ }^{\Uparrow}$ M. peterklaasi 2009 001, Costa Rica, Holland previously dried; 1 đ M. peterklaasi 2008 072, Costa Rica, 01/12/97, w/c Costa Rica. SJLC: 1 \& Megaphobema peterklaasi PEK2, died approx 2006, Ex Eddy Hijmensen.

M. robustum - MCZ: 1 ○ M. robustum 74298 Colombia, Dept. Meta, Carimagua, 370m, 18 May 1973, Mary Corn, in cow pasture Savannah. OUMNH: 4 q $M$. robustum 2008 072, Colombia, w/c 1997 [see fig. 15 for spermathecae of ROB3, 1 ㅇ M. robustum O.P. Cambridge coll, Drawer 9; 1 q M. robustum, Hope / Westwood coll, Drawer 23; 1 $M$. robustum, O.P. Cambridge coll, Drawer 46. SJLC: 1 ○ M. robustum, Colombia, pet trade, died 2013 don. Craig Mackay; 1 ㅇ $M$. robustum ROB5, died n.II.2014, Ex Stuart Longhorn; 1 Juv. M. robustum ROB5, died n.XI.2001, Ex Stuart Longhorn.

M. teceae - OUMNH: 1 o M. teceae 2008 072, Brazil, Manaus, died 01/01/08 Ex Ken Matzen; 1 q M. teceae, 2009 001, Brazil, Manaus, died 01/01/09, Ex K. Matzen 2008.

M. velvetosoma - OUMNH: 1 ○ M. velvetosoma VEL7, died 12.06.09, Ex Ray Gabriel; 1 q M. velvetosoma 2008 072, W/c Ecuador (importer Erato Holland) 1997 w/c., 1 + $M$. velvetosoma, VEL6, died 18.04.12 Ecuador, Ex John Chambers. SJLC: 1 \& M. velvetosoma VEL5, died 25.IX.15, Ex Stuart Longhorn; 1 imm $M$. velvetosoma VEL1, died 15.07.01, Ex WC import Paul Stevens, Tena, Ecuador.

\section{Theraphosa specimens:}

T. apophysis-BMNH: 5 \& \& 1 ๙ T. apophysis Venezuela, Roraima. Coll. Ian Wallace. 13.11.90, det. A.M. Smith. OUMNH: 3 T T. apophysis, 2007 064, pet trade, c/b.

T. stirmi - BMNH: 1 q T. stirmi [labelled T. blondi] 1939.3.24.42 British Guiana (=Guyana), New River (East Berbice-Corentyne). Jan-March 1938, Purch. C.A.Hudeson; 1 of \& 1 q T. stirmi [labelled T. blondi] Carl Davis. No data; 1 ô T. stirmi [labelled T. blondi] British Guiana (=Guyana). 2¹9'05.0” N $59^{\circ} 22^{\prime} 33.5^{\prime \prime W}$ (=Upper Takutu-Upper Essequibo, Region of Isherton, south Rupununi), G.McDonnell 1933; 1 \% T. stirmi [labelled T. blondi] Guyana, CuyuniMazaruni, Upper Waruma. 11.8.1971. M.Lyes Coll. (=British Roraima Expedition), det as T. blondi by W.Bücherl; 1 q T. stirmi [labelled T. blondi] Guyana, (Cuyuni-Mazaruni), Upper Mazaruni, wet trail after rain $3500 \mathrm{ft}$. British Roraima Expedition 27.8.1971. M.Lyes Coll. det as T. blondi by W.Bücherl; 1 juv. British 
Roraima Expedition, M.Lyes coll. det. T. blondi by W.Bücherl; 1 † Theraphosa cf. strimi [labelled T. blondi] Brazil, State of Amazonas, Environs of Yanomami village of Watoriki, close to (Rio) Demini, FUNAI post. $1^{\circ} 31^{\prime} \mathrm{N} 62^{\circ} 49^{\prime} \mathrm{W}$. OUMNH: 1 O Imm T. stirmi (accessioned as sp., Guyana) 2007 064, 10/03/09, Imported Lee Arden (Spidershop UK); 1 q T. stirmi [sold as sp. burgundy] 2009 007, Guyana, 10/03/09, Imported Lee Arden (Spidershop UK); 1 Imm T. stirmi (as Theraphosa sp, Guyana) 2009 007, 10/03/09, Imported Lee Arden Spidershop UK; 1 O Imm T. stirmi [sold as sp. burgundy], 2009 051, Guyana, Imported Lee Arden (Spidershop UK).

T. blondi-OUMNH: $1 \curvearrowright$ T. blondi 2009 007, pet trade, Guy Tansley; 1 T. blondi 2009 001, pet trade, c/b 1996 died 01/10/08 K Halsey; 1 P T. blondi, Hope coll; 1 § T. blondi O.P.Cambridge coll, Drawer 48; 1 त Imm T. blondi 2007 064, pet trade, M Walters stuck in moult. SJLC: 1 o T. blondi, died 2013. W/c French Guiana, ExJ.M. Verdez.

T. sp. (indet). - BMNH: + Theraphosa sp. indet. [labelled T. leblondi] 1968.2.27.10. British Guiana (=Guyana). Coll. J.W Lester; 1 o Theraphosa indet. [labelled as T. blondi] Brazil, St. Paulo (?). S.Roburn. No further data; 1 đ Theraphosa indet. [labelled T. blondi] No further data.

\section{Other specimens:}

PMY: 1 Imm $\widehat{ }{ }^{\lambda}$ Pamphobeteus? sp. Guayaquil, Ecuador, Banana Distribution Company, New Haven, 30.iii.1951 [was misidentified by Petrunkevitch as S. rubronitens]; 1 ㅇ Phormictopus sp, Yale-Fla. Haiti Exped. Feb., March, April 1959 P. S. Humphrey, [was misidentified by Petrunkevitch as $S$. rubronitens].

MNHN: 1 T Theraphosinae indet, AR 4850 MNHN (Simon Collection), 'Panama and Guatemala' leg. unknown (same jar as holotype for S. panamense). 